\title{
Bases para una epistemología general de las ciencias sociales
}

\author{
Manuel MARTIN SERRANO
}

REFERENCIA PARA LAS CITAS DE ESTA PUBLICACIÓN Y DE SUS CONTENIDOS:

MARTIN SERRANO, Manuel (1978): "Bases para una epistemología general de las ciencias sociales", Reis (Revista Española de Investigaciones Sociológicas), no 3, pp. 17-55. Disponible en: http://www.reis.cis.es/REIS/PDF/REIS 003 04.pdf

Recuperado el_de de 2 de http://eprints.ucm.es/13170/

UTILIZACIÓN DE ESTE DEPÓSITO:

Usted es libre de copiar, distribuir y comunicar públicamente la obra bajo las siguientes condiciones, que corresponden a la licencia Creative Commons que protege este texto:

Reconocimiento. Debe reconocer y citar al autor original, utilizando la "REFERENCIA PARA LAS CITAS DE ESTA PUBLICACION Y DE SUS CONTENIDOS" (véase recuadro superior).

No comercial. No puede utilizar esta obra para fines comerciales.

Sin obras derivadas. No se puede alterar, transformar, o generar una obra derivada a partir de esta obra. 


\title{
Reading TEORÍA DE LA COMUNICACIÓN: LA TEORÍA
}

\author{
Presentación y estudio documental por Daniel Franco Romo
}

En E-Prints se tiene acceso a una selección de la obra original de Manuel Martín Serrano (véase: "Publicaciones de Manuel Martín Serrano disponibles en E-Prints. Selección sistematizada"*, en http://eprints.ucm.es/11107/).

Una parte importante de dicha obra está dedicada a producir TEORÍA DE LA COMUNICACIÓN. Las publicaciones referidas a este campo que se han puesto a disposición de los usuarios de E-Prints, están organizadas en dos Reading: TEORÍA DE LA COMUNICACIÓN: LA TEORÍA, que es el que ahora se presenta; y MÉTODOS PARA LA TEORÍA DE LA COMUNICACIÓN.

El Reading TEORÍA DE LA COMUNICACIÓN: LA TEORÍA incluye:

\section{Publicaciones con los fundamentos epistemológicos y metodológicos necesarios para producir teoría de la comunicación}

Cuando Manuel Martín Serrano llega a la teoría de la comunicación, ya ha elaborado y difundido otras innovaciones epistemológicas y metodológicas que abrieron el camino:

- Había planteado el estudio de los comportamientos, como resultado de las dinámicas entre los actos ejecutivos y comunicativos (cf. "Actos ejecutivos y actos expresivos", http://eprints.ucm.es/13101/). Una visión más amplia en el Reading ANÁLISIS DE LOS COMPORTAMIENTOS: LOS ACTOS EJECUTIVOS Y COMUNICATIVOS (véase su contenido en "Publicaciones de Manuel Martín Serrano sobre los comportamientos disponibles en E-Prints", http://eprints.ucm.es/13288/).

- Había identificado los sistemas finalizados por la intervención social como el espacio propio de las ciencias sociales, elaborando la teoría y la metodología específicas (cf. "Una epistemología de los sistemas finalizados por la intervención humana. El análisis praxeológico de la reproducción y el cambio de los sistemas sociales", http://eprints.ucm.es/13125/).

- Con La mediación social (Madrid: Akal, 1977, 2008), crea el paradigma para investigar cómo se relacionan los recursos a la información, a la organización y a la acción social, en el funcionamiento y el cambio de las sociedades (cf. "Prólogo para La mediación social en la era de la globalización", http://eprints.ucm.es/10651/). Una visión más completa en el Reading TEORÍA DE LA MEDIACIÓN SOCIAL (véase su contenido en "Publicaciones de Manuel Martín Serrano sobre mediaciones disponibles en E-Prints”, http://eprints.ucm.es/13287/).

El autor expone los nuevos supuestos sobre los que construir la teoría y anticipa el plan de trabajos teóricos sobre comunicación, que irá desarrollando en los años posteriores, en el artículo "Bases para una epistemología general de las ciencias sociales" (este depósito).

\section{Publicaciones referidas a las dimensiones específicas de la comunicación y de sus teorías}

Manuel Martín Serrano ha llevado a cabo un giro epistemológico para el despegue de las ciencias de la comunicación, que inicia hacia 1977, cuando obtiene la cátedra de Teoría de la Comunicación y funda el Departamento del mismo nombre, en la Universidad Complutense de Madrid. Enuncia el programa que había que emprender para crear la Teoría de la Comunicación y ha persistido en esa tarea hasta considerar, en el año 2007, que ya está cumplida.

Esa refundación teórica de la comunicación requiere que se comience aclarando cuáles son los componentes necesarios para que cualquier interacción comunicativa pueda llevarse a término. El autor los identifica en Teoría de la comunicación. I. Epistemología y análisis de la referencia (Madrid: Alberto Corazón, 1981). Aquí se reproducen dos descripciones que proceden de Teoría de la comunicación. La comunicación, la vida y la sociedad (Madrid: McGraw-Hill, 2007). Son: "Los elementos cuya naturaleza estudia la teoría de la comunicación" (http://eprints.ucm.es/13144/) y "Los componentes que están implicados en todas las interacciones comunicativas" (http://eprints.ucm.es/13120/). 
En el mencionado libro Teoría de la comunicación. I. Epistemología y análisis de la referencia, aparecido en 1981, Manuel Martín Serrano ha creado una de las propuestas teóricas más completas e influyentes en el ámbito de las ciencias de la comunicación. Aquí se ha depositado un capítulo y una reseña (escrita por el Prof. Dr. Santiago Montes) dedicados a "El modelo dialéctico de la comunicación" (http://eprints.ucm.es/13116/), que es una de las aportaciones más conocidas del autor.

Manuel Martín Serrano continúa la andadura teórica aclarando qué es y qué no es comunicación. Plantea "La pregunta que funda la teoría de la comunicación: ¿cómo es posible que la comunicación sea posible?" (http://eprints.ucm.es/13117/).

Veinticinco años más tarde (en el año 2007), considera que ya es posible hacer teoría de la comunicación con procedimientos científicos. Véase en "Lo que hace por la comunicación una buena teoría" (http://eprints.ucm.es/13118/) y en “¿Para qué sirve estudiar Teoría de la Comunicación?” (http://eprints.ucm.es/13145/). El balance de los logros alcanzados está en el capítulo 23 de Teoría de la comunicación. La comunicación, la vida y la sociedad.

\section{Publicaciones para producir teoría de la comunicación que sirva de fundamento en el estudio de todas las interacciones comunicativas}

La comunicación es una capacidad humana que ha contribuido decisivamente a la aparición de nuestra especie (cf. "La comunicación en la existencia de la humanidad y de sus sociedades", http://eprints.ucm.es/13112/) y que tiene importantes diferencias con respecto a las comunicaciones animales (cf. "Lo específicamente humano de la comunicación humana", http://eprints.ucm.es/13111/). Una visión más completa en el Reading LA COMUNICACIÓN HUMANA. ORÍGENES Y CARACTERÍSTICAS (véase su contenido en "Publicaciones de Manuel Martín Serrano sobre la comunicación disponibles en EPrints", http://eprints.ucm.es/13289/).

Pero las comunicaciones animales y humanas tienen fundamentos comunes y las características de las segundas son inteligibles cuando se desvelan los vínculos evolutivos que tienen con las primeras. Por lo tanto, la Teoría de la Comunicación tiene que ser adecuada para fundamentar todas las modalidades de interacciones comunicativas. Manuel Martín Serrano plantea y asume este desafío teórico, cuyos resultados se documentan en el Reading LOS ORÍGENES Y LA NATURALEZA DE LA COMUNICACIÓN (véase su contenido en "Publicaciones de Manuel Martín Serrano sobre la comunicación disponibles en EPrints", http://eprints.ucm.es/13289/). En este que ahora se presenta, se han seleccionado textos del autor que muestran las razones epistemológicas de esa refundación teórica: "Campo científico al que pertenecen los fenómenos comunicativos" (http://eprints.ucm.es/12979/); "El lugar de la teoría de la comunicación entre los saberes" (http://eprints.ucm.es/12980/) (depósito que incluye también el estudio del Prof. Dr. Luis Alfonso Castro Nogueira sobre Teoría de la Comunicación. La comunicación la vida y la sociedad); y "El «status» científico de la teoría de la comunicación en las ciencias humanas" (http://eprints.ucm.es/12981/).

\section{REFERENCIAS para enlazar este documento con los que cita y con aquellos que le citan}

- "La comunicación NO es una alternativa autónoma respecto al sistema de producción y de reproducción social" (http://eprints.ucm.es/11049/)

- "La mediación social y los enfoques de la teoría de la comunicación", por Miquel de MORAGAS SPA (http://www.ucm.es/info/mediars/MediacioneS1/Indice/MoragasMiquel/moragasmiquel.html).

- "La nueva era no va a ser de la comunicación, sino la de la conexión” (http://eprints.ucm.es/11065/)

- “Cuándo el valor de cambio de la información puede ser medido” (http://eprints.ucm.es/11067/)

- "La ampliación de la realidad en la que vivimos con otro universo virtual" (http://eprints.ucm.es/11069/)

- “Dialéctica, comunicación, mediación" (http://eprints.ucm.es/13254/) 
- “Las formas posibles de interacción” (http://eprints.ucm.es/13103/)

- "Indicaciones instrumentales y referidas a los efectos de la interacción" (http://eprints.ucm.es/13104/)

- “Acción/comunicación, en las ciencias y en los comportamientos" (http://eprints.ucm.es/13106/)

- “Las relaciones macrosociológicas entre acción y comunicación” (http://eprints.ucm.es/13107/)

- "Perspectivas que ofrecen los nuevos modelos de investigación para las ciencias sociales" (http://eprints.ucm.es/13185/)

- "La epistemología de la comunicación a los cuarenta años de su nacimiento" (http://eprints.ucm.es/13238/)

- "Presentación de la Teoría Social de la Comunicación” (http://eprints.ucm.es/13237/)

*Esta selección y sistematización de publicaciones de Manuel Martín Serrano, así como los análisis que les acompañan, se basa principalmente en los estudios realizados por los especialistas que han participado en dos monográficos dedicados a la obra del autor: el primero editado por Anthropos y preparado por Esteban Mate y el segundo por Chasqui, coordinado por Francisco Bernete. También se han localizado y utilizado numerosas reseñas que están publicadas en otras revistas científicas. El investigador Daniel Franco Romo ha planificado y supervisado la ejecución de todo el proyecto. 


\section{BASES PARA UNA EPISTEMOLOGIA GENERAL DE LAS CIENCIAS SOCIALES}

\section{CONTENIDO DE ESTA COLABORACION}

La introducción a este número monográfico ha mostrado que los nuevos métodos proceden, generalmente, de la semiología o semiótica, de la teoría de sistemas y de la teoría de la información. He hecho las siguientès afirmaciones, que ahora se trata de probar:

I. Cada una de las metodologías ha surgido de campos científicos distintos, y se ha interesado en problemas diferentes. Sin embargo, todas ellas pueden compartir unos fundamentos epistemológicos comunes, los cuales las diferencian de otras metodologías. En la parte primera de esta colaboración analizo cuáles son esos fundamentos.

II. Es posible, y necesario, un trabajo sistemático que desarrolle tales características metodológicas comunes. En la parte segunda de este estudio abordo el tema, propongo un análisis y sugiero una terminología, haciendo uso, como instrumento heurístico, de una lógica dialéctica.

III. 1. La teoría de la información, el análisis de sistemas, y ahora, la semiología, han aspirado sucesivamente a constituirse en el modelo epistemológico general de las ciencias humanas. Sin embargo, ninguna de estas

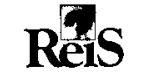

3/78 pp. 17-55 
metodologías está en condiciones de lograr esta pretensión, porque son métodos particulares, de aplicación exclusiva a determinadas expresiones de la actividad humana. El capítulo III.1 muestra las razones por las que es preciso buscar el paradigma de las ciencias sociales en una metodología más general, que integre y supere a cada una de las particulares.

III. 2. La integración del análisis de sistemas, la teoría de la información y la semiología en un modelo general significa necesariamente el recurso a una teoría de la comunicación. Si efectivamente se consiguiese la síntesis metodológica que propongo, tal vez podría aceptarse, a título de hipótesis de trabajo, que el modelo comunicacional puede llegar a proporcionar, en el futuro, el paradigma epistemológico que necesitan las ciencias humanas. Aunque el programa que sugiero ofrece trabajo a los especialistas en teoría del conocimiento durante bastantes años, ya es posible comprobar si la teoría de la comunicación puede cumplir los requisitos mínimos necesarios para desempeñar la función de una metodología general, y proponer, desde ahora, algunas vías para su desarrollo. Tal es el contenido de este último capítulo.

\section{FUNDAMENTOS EPISTEMOLOGICOS COMUNES A LA SEMIO- LOGIA, EL ANALISIS DE SISTEMAS, LA TEORIA DE LA, INFOR- MACION Y LOS METODOS QUE DE ELLOS DERIVAN}

1. Cada uno de estos métodos interpreta el conocimiento sobre el sistema como equivalente al control que se posee sobre su funcionamiento

a) Todo modelo teórico es, a la vez, un modelo operacional

Los métodos de referencia intentan conseguir una aproximación entre la representación del conocimiento (sobre el sistema) y la representación del funcionamiento (del sistema). Este enfoque permite que, en algunos casos, el modelo teórico que expresa el conocimiento sea equivalente al modelo operacional que explica el comportamiento del sistema ${ }^{1}$. Esta cualidad del modelo se denomina isomorfismo.

Así, el conocimiento de la estructura lógica de un lenguaje permite la generación de todos los discursos posibles a partir del empleo de los códigos de formación de textos; las reglas sociales que controlan el intercambio de mujeres y bienes explican la estructura del sistema de

' Los ejemplos habituales se refieren al código de las señales de tráfico, isomorfo del código que rige su funcionamiento. Estos ejemplos poseen interés didáctico, pero son demasiado simples para explicar los problemas que interesan en ciencias humanas. 
parentesco; el control sobre el volumen de información que puede transmitir un sistema de señales depende del conocimiento que se posea sobre la redundancia del sistema, etc.

Los modelos teóricos que son isomorfos de los modelos funcionales son los únicos que se consideran completamente satisfactorios, desde el punto de vista del conocimiento del sistema y del control sobre el sistema. Esta clase de modelos, a la vez teóricos y funcionales, son analíticos, prediptivos y operacionales; es decir, son modelos praxeológicos ${ }^{2}$.

\section{b) Una única lógica puede dar cuenta de la organización, el conocimiento y la acción}

Cuando aún no se ha logrado ese isomorfismo entre modelo teórico (sobre el sistema) y modelo de comportamiento (del sistema), se atribuye a un conocimiento todavía imperfecto; pero en ningún caso a una imposibilidad lógica de producir un único modelo que sea a la vez expresión funcional, explicación teórica y modelo operacional del sistema ${ }^{3}$.

La ignorancia se valora como una circunstancia bistórica, término que designa una doble historicidad: aquella que afecta a las ciencias y la que afecta a sus objetos:

$\left.b_{1}\right)$ La ignorancia motivada porque el estado de desarrollo de la ciencia es insuficiente, surge de alguna de estas razones:

- No se han identificado todavía los componentes del sistema que son pertinentes para comprender su funcionamiento.

- No se han objetivado las reglas que explican las relaciones (lógicas y funcionales) entre esos componentes.

2 Aunque las ciencias humanas estén todavía lejos de este desideratum epistemológico, no existe razón alguna para que el concepto de ciencia hacia el que se dirigen los esfuerzos teóricos, tenga que ser menos exigente que el concepto de ciencia que se acepta en las ciencias de la naturaleza.

${ }^{3}$ La aceptación de la hipótesis del isomorfismo entre código funcional del sistema y código del modelo teórico que explica el sistema significa que la misma lógica se considera válida para explicar las prácticas y el raciocinio, los procesos reales y los procesos cognitivos. Esta hipótesis se considera aplicable tanto en el estudio de la sociedad como de la naturaleza:

- Traducida en el lenguaje de las ciencias físicas, la energía y la información se consideran lógicamente equiparables, en cuanto que la segunda es una forma de energía especializada en el control sobre el funcionamiento del sistema.

- Traducida en el lenguaje de las ciencias sociales, significa que el sistema de la acción y el sistema de las representaciones se consideran lógicamente equiparables, en cuanto que la representación es una forma de acción especializada en organizar el sistema. 
- No se conocen todavía las relaciones que existen entre el sistema que se estudia y otros sistemas que le afectan.

$b_{2}$ ) La ignorancia motivada porque el estado de desarrollo del sistema es incompleto tiene la siguiente explicación:

En el dominio de las ciencias humanas, ciertos sistemas no desvelan sus componentes, sus reglas y sus interacciones hasta que el sistema ha llegado a un nivel de evolución suficiente. Así ha ocurrido, por ejemplo, con las formas de producción. Por tanto, la posibilidad de llegar a identificar los componentes de un sistema, sus reglas de funcionamiento y sus relaciones con otros sistemas, no dependen solamente de la capacidad de un científico; esa posibilidad también está determinada históricamente.

\section{c) Los nuevos métodos pertenecen a una epistemología basada en la praxis}

Unos métodos que son al mismo tiempo instrumentos de conocimiento y de intervención sobre la realidad merecen muy bien el título de métodos praxeológicos, entendiendo el término «praxis» en su sentido original: el conocimiento de la realidad sirve para actuar sobre ella, modificándola; y la modificación de la realidad sirve para transformar el conocimiento ${ }^{4}$.

La introducción de estos supuestos epistemológicos en ciencias sociales obliga a una redefinición de su objeto formal. Desde el punto de vista de una epistemología praxeológica, las ciencias sociales se ocupan del conocimiento que permite controlar la reproducción y el cambio de los sistemas sociales.

Conviene distinguir los modelos teóricos que cumplen a la vez funciones cognitivas y funciones de control de la realidad, de los modelos puramente teóricos o puramente prácticos. Propongo que los modelos característicos de una epistemología praxeológica se denominen «sistemas de análisis (praxeológico)».

\section{Los métodos de referencia coinciden en que cada uno de ellos trabajan con sistemas de análisis beterogéneos}

\section{d) Los métodos de referencia no pueden distinguirse entre si en función de sus objetos materiales}

A partir del momento en que los métodos praxeológicos - la semiología,

- La exigencia de isomorfismo entre la organización objetiva del sistema - por ejemplo, una sociedad- $-\mathrm{y}$ el modelo teórico que expresa el funcionamiento de ese sistema, plantea numerosas cuestiones epistemológicas referidas a la determinación de las ciencias respecto a sus objetos. Como en un trabajo anterior he estudiado con detalle esos problemas en el dominio de las ciencias sociales, me permito remitir al lector interesado en este tema, a lo ya escrito: "Libertad y predicción en las ciencias sociales, analizadas desde una perspectiva cibernética", Revista de Estudios Sociales, enero-abril 1973, núm. 7, 153-169. 
el análisis de sistemas, la teoría de la información y sus derivados- se aplican al estudio de sistemas de análisis que se refieren a los hombres y sus productos, tienen que trabajar con componentes heterogéneos ${ }^{5}$.

Por ejemplo, para estudiar el sistema de análisis de la neurosis hay que trabajar simultáneamente con componentes que son seres humanos, componentes que son necesidades instintivas, componentes que son resistencias del medio social; para estudiar el sistema de análisis de la demanda hay que trabajar con componentes que son ingresos, componentes que son productos, componentes que son imágenes de los productos, componentes que son aspiraciones sociales, componentes que son necesidades materiales.

Conviene tener muy en cuenta esta característica epistemológica de estos métodos, porque de ella surgen importantes problemas que determinan la validez de los sistemas de análisis praxeológico, como veremos más tarde.

Las ciencias que operan con componentes heterogéneos no pueden ser separadas en función de sus distintos objetos materiales. Por ejemplo, la única condición necesaria para que un dato de la realidad deba ser considerado como «materia sociológica» reside en que ese dato se transforme, con cualesquiera otros datos, como consecuencia del funcionamiento de un sistema social, o que su reproducción sea un requisito imprescindible para dicho funcionamiento.

En la perspectiva praxeológica que estamos describiendo, también es necesaria una reformulación del objeto material de las ciencias sociales. Un sistema social está constituido por el repertorio completo de aquellos componentes que se transforman o se reproducen de manera solidaria a lo largo de la trayectoria del sistema ${ }^{6}$, desde su origen basta su desaparición o mutación ?.

Por ejemplo, los delitos que se cometen en una comunidad y los códigos jurídicos de esa comunidad (junto a otros datos) forman parte del mismo sistema de análisis, en la medida que la reproducción o el cambio a un nivel afecta al otro.

${ }^{5}$ Lo cual no quiere decir que esas metodologías no puedan utilizarse para estudiar sistemas de análisis homogéneos: por ejemplo, los tres métodos pueden emplearse exclusivamente para analizar relaciones sintácticas (formales). Pero estos usos tecnológicos están, en esta ocasión, al margen de la problemática que aquí se estudia.

' La trayectoria de un sistema está constituida por todos los estados sucesivos que puede adoptar a lo largo de su historia, hasta su desaparición o transformación en otro sistema (cfr. pág. 30-11).

T La mutación es la transformación del significado de un sistema conservando su forma. 
Del mismo modo:

a) Los datos correspondientes a las variantes fonéticas del habla; b) los datos correspondientes al nivel del discurso; c) los datos correspondientes al nivel de la lengua; d) los datos correspondientes a los objetivos que persigue el locutor; son datos situados a distintos planos de expresión, representación, motivación; pero desde el punto de vista del sistema referido al uso de la palabra con fines comunicativos, deben ser considerados como componentes solidarios de un único sistema ${ }^{8}$.

\section{e) Conceptos de «pertinencia» y sus requisitos}

En resumidas cuentas, los componentes que entran a formar parte de un sistema social se determinan (al mismo tiempo):

a) En función de su capacidad de discriminación a nivel teórico, gracias a la cual puede comprenderse y explicarse el sistema.

b) En función de su capacidad de diferenciación a nivel práctico, gracias a la cual puede funcionar y perpetuarse el sistema. Ambas capacidades coinciden en el concepto de pertinencia.

Para establecer la pertinencia de los componentes de un sistema es necesario asegurarse de la significación y validez de los componentes. Del mismo modo, es necesario demostrar la pertinencia del propio sistema de análisis, en cuanto instrumento teórico y operativo.

La praxeología concibe los problemas de significación y validez en términos algo diferentes a los que se utilizan en los métodos estadísticos:

- En los métodos praxeológicos un componente significativo también debe discriminar. Pero esta función no corresponde necesariamente al componente más frecuente, como suele ocurrir en los métodos estadísticos. En un sistema de análisis praxeológico, la discriminación puede introducirse incluso por la ausencia significativa de un componente, como ocurre, por ejemplo, en el lenguaje y en la organización social.

- Un sistema de análisis válido también debe poseer consistencia formal (debe ser «un lenguaje bien construido» en términos neopositivistas). Pero en los métodos praxeológicos el concepto de consistencia formal se interpreta en términos matriciales. En estas metodologías hay que trabajar con el sistema de variantes (sistema de estructuras formales) que engendra

${ }^{8}$ Lo cual no impide que, por ejemplo, los datos fonéticos puedan ser analizados independientemente como componentes de un subsistema. Este análisis por separado de los fonemas puede desarrollarse hasta el nivel en el que sus variaciones tengan que ser explicadas por la existencia de datos pertenecientes a alguno de los otros subsistemas indicados. 
la matriz de componentes. El modelo de análisis debe generar todas las posibles alternativas cognitivas que pueden ( $\mathrm{y}$ deben) ser tomadas en cuenta.

- Un sistema de análisis válido también debe poder ser contrastado con la experiencia. Pero el concepto de experiencia se interpreta en términos históricos. Aunque todo modelo válido debe de remitir a un referente para ser contrastado, ese referente puede todavía no existir ${ }^{9}$. Incluso es posible que la validez de un sistema de análisis se pruebe por la experiencia de un referente que nunca puede llegar a existir ${ }^{10}$.

3. Los métodos praxeológicos coinciden en que cada uno de ellos «trabaja con objetos finalizados»"

\section{f) Concepto de «objeto finalizado»}

Tanto los objetos que intervienen como componentes de los sistemas de análisis como los objetos que son referencia del sistema suelen ser objetos finalizados.

Un objeto finalizado es toda cosa sujeta a la intervención humana.

Están finalizados todos los sistemas de análisis y todos los referentes cuyos componentes son ideas, conceptos, representaciones, actividades, productos, hechos concebidos o producidos por el hombre, y todos los componentes no concebidos o no producidos por el hombre, de los que éste se apropie o trate de servirse.

Así, están finalizados los signos del lenguaje natural, por las necesidades e intenciones - colectivas o individuales- que determinan uno $\mathrm{u}$ otro manejo del discurso; y están generalmente finalizados los referentes del discurso. Están finalizados los propios sujetos humanos que asumen roles en cualquier sistema de análisis social: por ejemplo, «sanos» y «enfermos»; y está finalizada la referencia del sistema social, por ejemplo, «normalidad» $\mathrm{y}$ «anormalidad», etc.

- No siempre la existencia de ese referente es un hecho observable por ahora: por ejemplo, la existencia real de alguna socidad comunista es la referencia obligatoria para probar la validez del modelo de análisis marxista; el hecho de que esa sociedad no exista no quiere decir que el modelo sea inválido, sino que todavía no puede ser validado.

${ }_{10}$ Por ejemplo, las funciones atribuidas por la mitología a ciertos seres míticos, como el unicornio, y la experiencia de su inexistencia real permiten establecer referencias adecuadas para validar sistemas de análisis que designan las cualidades de esos objetos culturales.

"Un análisis de concepto de finalización, desde una perspectiva teórica y metodológica, en M. Martin Serrano, "Aplicación de la teoría y el método sistemático en ciencias sociales", REOP, 42, octubre-diciembre 1975. 


\section{g) Requisitos para el análisis de objetos finalizados}

Los objetos finalizados tienen la característica de que poseen un valor que les viene conferido por el proyecto humano, individual o social. Por otra parte, el valor de un objeto finalizado es una función de la realidad histórica de la que forma parte, es decir, cambia con el tiempo, en la medida que cambian los proyectos humanos, los objetos a los que se aplican y los conocimientos e ideas que dirigen las prácticas sociales:

- A consecuencia del carácter histórico que poseen estos objetos, están sometidos al cambio y la mutación. Por tanto, el criterio de objetividad que se puede utilizar en estos métodos remite a un examen renovado del estado en el que se encuentran los referentes ${ }^{12}$.

- A consecuencia del carácter histórico que posee el propio conocimiento, el concepto de objetividad que se puede utilizar en estos métodos, remite a un examen renovado de la escala de observación desde la cual se está elaborando el sistema de análisis ${ }^{13}$.

- A consecuencia del carácter práctico que posee el avance científico que se proponen estos métodos, el concepto de objetividad que manejan exige un examen renovado de la centración-descentración del científico y de la sociedad, respecto al saber y el hacer que proporciona el sistema de análisis ${ }^{14}$.

El investigador que trabaja con estos métodos se ve en la necesidad de tomar en cuenta la solidaridad existente entre diversos planos existenciales, cognitivos y prácticos, planos que los métodos empíricos e hipotético-deductivos prefieren tratar por separado ${ }^{15}$.

El método praxeológico aspira a establecer las relaciones entre:

1) El plano de los referentes del sistema de análisis ( $P R$ ); plano que introduce como componentes de la realidad cuanto emerge del mundo natural, social y cognitivo en el que actúan los hombres.

12 En la sociedad, frecuentemente los referentes sufren cambios irreversibles; por ejemplo, aquellos referentes que están a nivel del acontecer. Un análisis de este tema en M. Martín Serrano, 1975 (O.C.).

${ }^{13}$ La escala de observación determina la referencia respecto a la cual es válido el sistema de análisis. Por ejemplo, si estudiamos las relaciones en un grupo de trabajo, el sistema de análisis remite a la escala de la dinámica de grupos; si estudiamos las actividades de los individuos que componen ese grupo, el sistema de análisis remite a la escala de las motivaciones individuales. Las observaciones son distintas, y no se puede explicar el funcionamiento de un nivel por los datos obtenidos a otro. Esta trasgresión también existe en los métodos que estoy tratando, como mostraré más tarde.

14 Del mismo modo que los juicios del observador y sus comportamientos quedan modificados por lo que observa, la escala de observación y el objeto observado se ven afectados por los juicios y comportamientos del observador.

is Como es obvio, resulta necesario recurrir a investigaciones particulares hasta el momento en el que sea posible una integración del ser, con el conocer y el hacer en un único sistema de análisis. 
2) El plano de los sistemas de análisis (PS); plano que introduce como componentes de las ciencias cuanto puede servir para el conocimiento y el control de los referentes.

3) El plano de las prácticas ( $P P$ ); plano que introduce como componentes de la acción social los usos alternativos que pueden hacerse de unos u otros sistemas de análisis, para intervenir sobre unos u otros referentes.

En consecuencia, las condiciones canónicas de demostración en estos métodos son particularmente exigentes:

A) Debe demostrarse la consistencia del sistema de análisis, es decir, la validez interna que posee el modelo desde el punto de vista de la pertinencia de sus componentes, y la adecuación de sus códigos.

B) Debe demostrarse la objetividad del sistema de análisis, es decir, la validez externa que posee el modelo para identificar un referente, explicarlo o permitir la intervención sobre él.

C) Debe demostrarse la conveniencia del sistema de análisis para intervenir sobre la realidad, toda vez que estas metodologías están concebidas para proporcionar el conocimiento que guíe la acción de los hombres y no para la mera especulación teórica. En consecuencia, un sistema de análisis no sólo incluye valores, sino que además depende de los valores ${ }^{16}$.

Las características comunes a los métodos praxeológicos que he señalado avalan la idea de que todos ellos comparten unos fundamentos epistemológicos comunes. El paso necesario para aproximar la semiología, el análisis de sistemas y la teoría de la información, en busca de un paradigma compartido, consiste en desarrollar un lenguaje metodológico que convenga a todos estos métodos, y en objetivar las reglas propias del método. Este es el objeto de la segunda parte de este trabajo.

\section{SISTEMATIZACION DEL METODO PRAXEOLOGICO}

1) Cada uno de los métodos praxeológicos de referencia (semántico, análisis de sistemas, informacional y sus variantes) es un método matricial que se aplica al estudio de sistemas de análisis.

1. Denomino métodos matriciales a aquellos que trabajan con conjuntos de componentes, estudiando el conjunto como una única unidad de análisis.

2. Por «componente» (c) designo todos los objetos incluidos en una misma matriz. Tales objetos pueden ser cosas, estados de las cosas, relaciones entre las cosas, atributos de las cosas; entendiendo "cosa» en el sentido más amplio, sin restricción alguna de sustancia: son «cosas» los números,

${ }^{16}$ Un examen detallado de esta cuestión en M. Martín Serrano (O. C.), 1973. 
las relaciones, los modelos, las teorías; los acontecimientos, los sucesos, las descripciones, las predicciones; los objetos naturales y los productos del trabajo humano; los seres imaginarios y los reales, animados o inanimados; las personas, los grupos, las organizaciones; los comportamientos, los intereses, los valores, los objetivos, etc.

Los componentes de una matriz pueden ser todos ellos objetos bomogéneos, es decir, de la misma clase. Por ejemplo, son homogéneos todos los signos de cada alfabeto; todos los votantes componentes de unas elecciones democráticas. Matrices con componentes beterogéneos son aquellas constituidas por objetos de distinta clase. Por ejemplo, son heterogéneas las expresiones, respecto a los contenidos de los lenguajes naturales; igualmente heterogéneos, los valores de uso respecto a los valores de cambio y ambos respecto a los cambistas, en el mercado.

3. Denomino «sistema de análisis» («S») a aquella matriz cuyos objetos componentes han sido seleccionados respecto a una misma referencia.

4. Por «referencia» entiendo cualquier objeto no incluido en la matriz del sistema de análisis; considerando «objeto» en el mismo amplio sentido que se ha indicado en 2.

De acuerdo con 2 hay dos clases de sistemas de matrices: sistemas bomogéneos y beterogéneos.

Ejemplos de sistemas homogéneos: el sistema fonético, constituido sólo por fonemas; el sistema de parentesco, constituido sólo por relaciones de filiación. Ejemplos de sistemas heterogéneos: el sistema de estratificación social, constituido por actores, status y roles; los sistemas ecológicos, constituidos por componentes naturales, artificiales, biológicos y sociales.

\section{A. ANálisis de la CONSISTENCIA de los sistemas}

2) Los métodos de referencia comparten un mismo criterio de «sistema de análisis».

5. Un conjunto de objetos puede constituirse válidamente en componentes de un sistema de análisis, cuando existe alguna solidaridad entre:

a) La forma en la que tales objetos aparecen relacionados entre sí en la matriz $(r)$.

b) Las funciones que desempeña cada objeto en la explicación del comportamiento del conjunto $(f)$.

a) El repertorio de las relaciones de los objetos en el conjunto determinan las estructuras del sistema $(\mathrm{O})$. 
b) El repertorio de las funciones de los objetos en el conjunto determinan las cualidades del sistema (C).

6. A partir de ahora reservo el nombre de «componentes del sistema» sólo para el repertorio de objetos que forman parte válidamente de un mismo sistema de análisis, y distingo, de acuerdo con 2 , entre componentes bomogéneos y beterogéneos.

Recapitulando estas definiciones, se comprueba que son adecuadas para caracterizar a los métodos de los que aquí se trata. Por ejemplo, la semiología es un método que se aplica a sistemas de análisis constituidos por signos, cuyas referencias pueden provenir de cualquier objeto. La teoría de sistemas es un método que se aplica a sistemas de análisis constituidos por vectores, cuyas referencias son los cambios que aparecen en otros sistemas. La teoría de la información es un método que se aplica a sistemas de análisis constituidos por señales, cuyos referentes son valores.

De acuerdo con 5 , la condición de validez para atribuir a un conjunto de objetos el carácter de componentes de un sistemas se da cuando

$$
\mathrm{O} \text { de } \mathrm{S} \longleftrightarrow \mathrm{C} \text { de } \mathrm{S}
$$

o lo que es lo mismo:

$$
r \text { de }\left(c_{1}, c_{2}, \ldots, c_{n}\right) \longleftrightarrow f \text { de }\left(c_{1}, c_{2}, \ldots, c_{n}\right)
$$

Significando el signo $«(\longleftrightarrow) »$ cualquier forma posible de interdependencia.

Por ejemplo, los fonemas son componentes válidos del sistema de análisis fonológico, porque sus posiciones determinan sus funciones; del mismo modo y por las mismas razones, los roles familiares son componentes válidos del sistema de análisis de la familia, y las edades de reproducción y fallecimiento son componentes válidos del sistema de análisis demográfico, etc.

En todas estas metodologías, una vez objetivado el referente, se trata de proponer un sistema de análisis. El trabajo se inicia estableciendo el repertorio de los componentes de $S$, es decir, el conjunto de aquellos objetos -y solamente aquellos objetos- que forman parte del sistema ${ }^{17}$.

1 Esta tarea de investigación puede parecer banal $\mathrm{y}$, sin embargo, son muy pocos los sistemas de análisis válidos que han llegado a identificarse; limitación que pone de manifiesto la dificultad de establecer los componentes pertinentes en los sistemas sociales. Por ejemplo, se conocen bien los componentes del sistema fonético en casi todas las lenguas vivas; en cambio, los componentes del sistema del contenido no han sido identificados en ninguna lengua natural. 
3) Cada uno de estos métodos utiliza los mismos criterios para identificar los componentes de los sistemas que estudian.

7. Las reglas para identificar la existencia de un componente en un sistema de análisis son las siguientes:

- $\mathrm{r}_{1}$ : un objeto es componente de un sistema de análisis cuando la presencia o ausencia de ese objeto resulta necesaria para explicar la diferencia de estructuras entre este y otro sistema, o las diferencias de estructura del mismo sistema a lo largo del tiempo.

- $\mathrm{r}_{2}$ : un objeto es componente de un sistema de análisis cuando la presencia o ausencia de ese objeto resulta necesaria para explicar las diferencias Ue cualidades entre ese y otro sistema, o las diferencias de cualidades del mismo sistema a lo largo del tiempo ${ }^{18}$.

Estas reglas pueden formalizarse como una ley:

8. Sólo son componentes de un sistema de análisis aquellos que cumplen una función de pertinencia.

Por función de pertinencia $(/ /)$ se entiende:

a) La introducción de una discriminación entre un sistema y otros sistemas:

$O S_{1} / / O S_{2} / / O S_{n} ;$ o bien $C S_{1} / / C S_{2} / / C S_{n}$

b) La introducción de una discriminación entre el repertorio posible de estructuras del mismo sistema,

$$
\begin{aligned}
& \mathrm{O}_{0} \mathrm{~S} / / \mathrm{O}_{\mathrm{l}} \mathrm{S} / / \ldots \mathrm{O}_{\mathrm{n}} \mathrm{S} \\
& \mathrm{t}_{\mathrm{o}} \rightarrow \mathrm{t}_{1} \rightarrow \ldots \rightarrow \mathrm{t}_{\mathrm{n}}
\end{aligned}
$$

c) La introducción de una discriminación entre el repertorio posible de cualidades del mismo sistema

$$
\begin{aligned}
& \mathrm{C}_{0} \mathrm{~S} / / \mathrm{C}_{1} \mathrm{~S} / / \ldots \mathrm{C}_{\mathrm{n}} \mathrm{S} \\
& \mathrm{t}_{\mathrm{o}} \rightarrow \mathrm{t}_{1} \rightarrow \ldots \rightarrow \mathrm{t}_{n}
\end{aligned}
$$

is De acuerdo con la definición de sistema que se ha adoptado en 5 , todo componente que resulta necesario para dar cuenta de una diferencia de estructura cumple una función diferencial desde el punto de vista de las cualidades del sistema, y viceversa. Por tanto, $r_{1}$ y $r_{2}$ son reglas de análisis alternativas y conmutativas. 
Ejemplos de identificación de componentes:

a) Basados en la constatación de diferencias entre sistemas: la existencia de los componentes «obrero asalariado» y «capitalista» resulta necesaria para explicar la diferencia entre la organización del sistema de producción capitalista y la organización de los sistemas de análisis de la producción feudal o comunista.

$\left.b^{\prime}\right)$ Basados en la constatación de diferencias estructurales: la existencia de los componentes «productos» y «valores de cambio» resulta necesaria para explicar las crisis periódicas y los períodos de acumulación, en la forma de producción capitalista.

c) Basados en la constatación de diferencias de cualidades en el mismo sistema: la existencia de componentes «capital fijo» y «capital variable» resulta necesario para explicar el cambio de cualidad del sistema de análisis de la producción capitalista; explican la trayectoria de este sistema desde el capitalismo agrario, al mercantil, industrial y monopolista.

Ejemplos de funciones de pertinencia:

a") La presencia o ausencia de ciertos componentes fonéticos, como el fonema /e/ es necesario para explicar las diferencias entre el sistema fonético inglés y español.

$b^{\prime \prime)}$ En algunos grupos sociales, la existencia o carencia de hermanos de uno u otro cónyuge determina las reglas de residencia para los esposos o los hijos. La ocurrencia o no ocurrencia de un período previo de acumulación explica, junto a otros factores, que ciertas sociedades lleguen a transformarse antes o después en sociedades industriales.

$\left.c^{\prime \prime}\right)$ La presencia o ausencia de luz roja y luz verde es necesaria para explicar la diferencia de cualidad en el sistema de señales luminosas de tráfico.

4) Todos los métodos que se están refiriendo son métodos de modelización

9. Denomino métodos de modelización a aquellos que estudian cada es. tado del sistema, en relación con el universo de estados que le son posibles al sistema de análisis; del mismo modo, analizan cada trayectoria del sistema, en relación con el universo de trayectorias que le son posibles al sistema de análisis.

Por ejemplo, la antropología estructural es un método de modelización porque pone en relación las formas del parentesco en un grupo determinado, con las formas alternativas de parentesco que existen en otros grupos y con las restantes formas que podrían imaginarse, combi- 
nando los mismos componentes (aunque tales formas nunca hayan existido en la realidad).

Los modelos de futuros "alternativos», "probables» y «previsibles», que analiza la teoría de sistemas, también son ejemplos de análisis de modelización.

Los modelos estereotipados de relato, en los medios de comunicación de masas, cuando se relacionan con modelos alternativos (que no son comunicados), pueden ser estudiados desde la metodología de una modelización.

10. A partir de ahora denomino «modelos de estados» $(E)$ al repertorio completo de estructuras y cualidades que puede adoptar un sistema de análisis. El modelo de los estados expresa todas las formas posibles de existir que son propias del sistema.

11. A partir de ahora denomino modelo de trayectorias $(T)$ al repertorio completo de sucesiones alternativas entre las distintas estructuras y cualidades que puede adoptar un sistema de análisis a lo largo del tiempo. El modelo de las trayectorias expresa todos los modos posibles de cambio que son propios del sistema.

12. El conocimiento de la combinación de estados y trayectorias constituye la representación canónica del sistema de análisis $(\xi)^{19}$.

13. Una transformada de un sistema de análisis es cualquier estado a lo largo de una trayectoria que forme parte de la representación canónica del sistema de análisis.

Evidentemente, la suma de las transformadas corresponde a $(\xi)$.

La representación canónica de un sistema de análisis se obtiene cuando se han identificado los componentes y las pertinencias.

Sea un sistema de análisis constituido por los siguientes componentes y pertinencias:

"Siendo $\xi=[\mathbf{E} \times \mathbf{T}]$

- lo que es lo mismo:

$\xi=[(\mathrm{O}, \mathrm{C}) \times \mathrm{T}]$ 
ESQUEMA 1

Componentes

\section{Pertinencias}

C el hijo

$\mathrm{C}_{1}$ amor //

$\mathrm{C}_{2}$ rechazo

Col el padre //

$\mathrm{C}_{\mathrm{o} 2}$ la madre

$\mathrm{C}_{\text {ool }}$ autoagresión //

$\mathrm{C}_{002}$ agresión a otros
Necesariamente debe haber un hijo que, necesariamente, o bien ama o bien rechaza (pero no ambas cosas);

necesariamente, o bien a un padre, o bien a una madre (pero no a ambos);

y que necesariamente reacciona: o bien autoculpándose, o bien culpando a otros.

Los estados posibles para este sistema y las trayectorias posibles son las siguientes (expresadas como un grafo):

\section{ESQUEMA 2}

\section{ESTADOS}

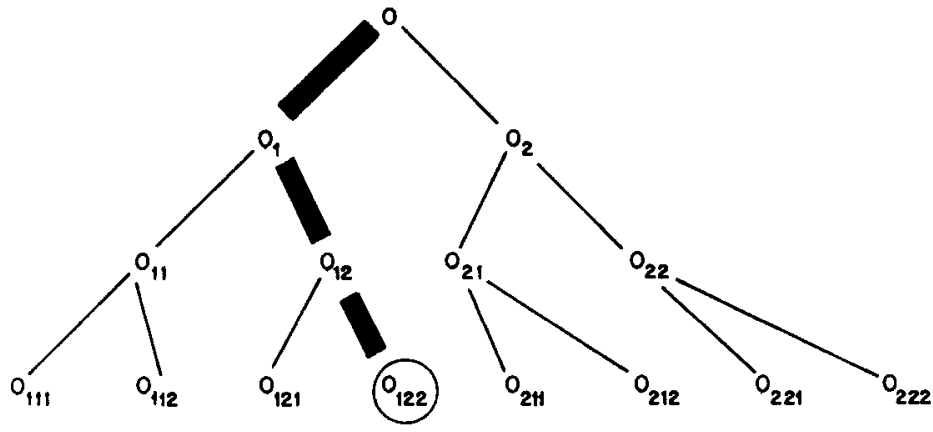

TRAYECTORIAS

Momento:

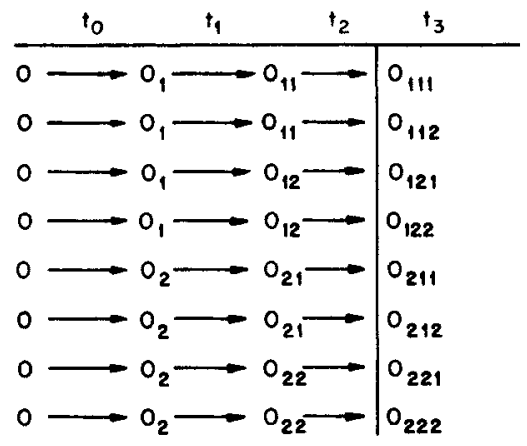


Supongamos que el componente hijo $(\mathrm{C})$ ama $\left(\mathrm{C}_{1}\right)$ a la madre $\left(\mathrm{C}_{\mathrm{o} 2}\right)$ y desplaza sus agresiones hacia otros $\left(\mathrm{C}_{002}\right)$. La representación de este comportamiento del sistema aparece marcada con la línea más gruesa en el grafo $E$. Esa derivación representa un estado posible del sistema a lo largo de una trayectoria; es decir, una transformada. Es fácil identificar, siguiendo las derivaciones del grafo, las otras transformadas alternativas que el sistema permite.

En este ejemplo he fabricado un sistema de análisis con muy pocos componentes y muy determinado, con el objeto de que generase una representación canónica muy fácilmente manejable. En la realidad, los sistemas de análisis que interesan a las ciencias humanas contienen un número mucho mayor de componentes, y las discriminaciones que introducen las pertinencias entre los componentes suelen ser más complicadas que una decisión binaria entre pares sucesivos de componentes. Si estudiamos sistemas de análisis como la lengua natural o los grupos sociales, será muy difícil llegar a objetivar la representación canónica del sistema, y sobre todo, poco útil. En la práctica, la generación de la representación canónica es innecesaria siempre que sea posible un método que permita determinar a priori cualquier posible transformada que permita el sistema; o, si se prefiere, es lo mismo conformarse con la capacidad de determinar a priori las transformaciones que no le son posibles al sistema. Así, el jugador de ajedrez no está interesado en el inventario de partidas de ajedrez, ni el usuario de la lengua en todas las oraciones que puede generar con los sujetos, los verbos y los complementos.

14. Cuando es posible sustituir la representación canónica del modelo de análisis por unas reglas de generación de transformadas, se dice que el sistema está codificado.

5) Todos estos métodos tratan de predecir el repertorio de transformadas de los sistemas que estudian, mediante la elaboración de códigos

15. Por código entiendo un repertorio de reglas que ponen en relación componentes y pertinencias, con el objeto de conocer a priori si una transformada del sistema pertenece o no a la representación canónica (del sistema) ${ }^{20}$.

16. Un código es completamente prediptivo cuando permite prever cual-

${ }^{20}$ Como es sabido, las reglas que pertenecen a un código válido generalmente poseen la cualidad de ser componentes de un sistema de segundo orden o metasistema. Analizando este metasistema como otro sistema de análisis se obtendrán las pertinencias correspondientes; con los nuevos componentes y pertinencias será posible elaborar un código de segundo orden, y así sucesivamente. Señalo esta cualidad de sistema propia de los códigos, sin otro comentario por el momento, para no desviar el desarrollo de este trabajo. 
quiera de las transformadas y sólo las transformadas que el sistema de análisis permite ${ }^{21}$.

17. El establecimiento de las reglas del código es una tarea relativamente sencilla en los sistemas cerrados; en cambio, resulta más difícil, y a veces objetivamente imposible, en los sistemas abiertos.

18. Por sistema cerrado (a otros sistemas) entiendo aquel sistema de análisis $\varangle \mathrm{S}$. cuyos estados dependen exclusivamente de las estructuras y cualidades del propio sistema, y cuyas trayectorias dependen exclusivamente de las sucesiones que adopta el propio sistema.

Nuevamente utilizo un ejemplo de sistema cerrado muy sencillo para explicar el concepto. Sea el sistema $\underline{S_{\mathrm{T}}}$ de señales de las luces de tráfico, reducido a cuatro componentes, sin intervención de otros elementos que introduzcan nuevas pertinencias (como podría ser la intervención de un guardia de tráfico).

\section{ESQUEMA 3}

\section{Sistema $S_{\mathrm{T}}$}

\section{Componentes}

$\mathrm{C}_{1}$ luz roja //

$\mathrm{C}_{2}$ luz verde
Pertinencias

Sólo $\mathrm{C}_{1}$ ó $\mathrm{C}_{2}$

$\mathrm{C}_{12} / / \mathrm{C}_{21}$
Co1 permiso para pasar //

$\mathrm{C}_{\mathrm{o} 2}$ prohibición de pasar
Si $C_{1}$, sólo $\mathrm{C}_{02}$

Si $\mathrm{C}_{2}$, sólo $\mathrm{C}_{\mathrm{o}}$

El código se contiene en una única regla $\overline{\mathrm{C}_{12} / / \mathrm{C}_{21}}$, que sirve para generar todas las transformadas que pertenecen a la representación canónica de $\overline{\mathrm{S}_{\mathbf{T}}}$.

19. Por sistema abierto (a otros sistemas) entiendo un sistema de análisis (-S-) parcialmente autónomo. En un sistema abierto los estados de-

${ }^{21}$ Se comprende que la única utilidad que tiene trabajar con códigos en vez de con representaciones canónicas es un principio de economía; el código sirve para reducir la variedad de lo posible a la concreción de la ley capaz de deducir - generar las transformadas del sistema. Cuando el código no tiene esa utilidad, más vale mostrar las cosas que codificarlas. 
penden en parte de las estructuras y cualidades del propio sistema, y las trayectorias dependen en parte de las sucesiones que adopta el propio sistema. Pero el sistema también está determinado por la intervención de otro u otros, cada uno de ellos capacitado para introducir pertinencias que pueden alterar el estado o la trayectoria del sistema.

La dificultad que presenta la codificación de los sistemas abiertos se pone de manifiesto en un ejemplo relativamente simple ( $y$ nuevamente simplificado por razones didácticas): las relaciones afectivas en el marco de la pareja, que designo como «(- $\left.\mathrm{S}_{\mathrm{f}}-\right)_{\text {»). }}$

Si ( $-\mathrm{S}_{\mathrm{L}}$-) fuese un sistema cerrado, no habría problema para identificar el código de sus transformadas. Pero las relaciones afectivas de la pareja se ven afectadas por la intervención de otros componentes y otras pertinencias que proceden de la influencia de otros sistemas; por ejemplo, influyen las relaciones con miembros de la familia extensa $\left(-\mathrm{S}_{\mathrm{F}}-\right.$ ), el trabajo $\left(-\mathrm{S}_{\mathrm{T}}-\right.$ ), las amistades $\left(-\mathrm{S}_{\mathrm{A}}-\dot{i}\right.$, etc.

ESQUEMA 4

$\left(-S_{\mathrm{f}}-\right)$

\section{Componentes}

Pertinencias

$-\mathrm{S}_{\mathrm{f}}-$

$\mathrm{C}_{1}$ Esposo //

$\mathrm{C}_{2}$ Esposa;

$\mathrm{C}_{1}$ y $\mathrm{C}_{2}$

$\mathrm{C}_{\mathrm{ol}}$ Amor //

$\mathrm{C}_{02}$ Odio //

$\mathrm{C}_{01}$ ó $\mathrm{C}_{02}$ ó $\mathrm{C}_{03}$

$\mathrm{C}_{03}$ indiferencia;

$\mathrm{C}_{\text {ool }}$ vida en común //

Si $\mathrm{C}_{\text {ol }}, \mathrm{C}_{\text {oot }}$

$\mathrm{C}_{\text {oo2 }}$ vida separada;

Si $\mathrm{C}_{02}$ ó $\mathrm{C}_{03}, \mathrm{C}_{002}$

$-S_{\mathrm{F}}-\quad$ Cooo1

$:::::$

Cooon

$-\mathrm{S}_{\mathrm{T}}-\mathrm{C}_{00001}$

$:::::$ :

Coooon

?

?

Cooooo 1

: : : : : : :

Cooooon 
El esquema 4 permite comprender que la codificación de $\left(-\mathrm{S}_{\mathrm{f}}\right)$ presupone el conocimiento de $\left(-\mathrm{S}_{\mathrm{F}}-\right),\left(-\mathrm{S}_{\mathrm{T}}-\right),\left(-\mathrm{S}_{\mathrm{A}}\right)$, etc. Esta tarea resulta inabordable la mayor parte de las veces.

En algunas ocasiones es posible sustituir el conocimiento de las pertinencias del sistema por el conocimiento de los comportamientos estadísticamente más probables que cabe asignar al efecto de otros sistemas. Por este procedimiento, llamado «de la caja negra», se llega a elaborar un código estadístico dotado de mayor o menor capacidad prediptiva, en función del grado de indeterminación que presente el sistema. De hecho, los modelos estadísticos que se utilizan en ciencias sociales, cuando parten de un sistema de análisis bien definido, son variedades de códigos estadísticos.

Los sistemas cerrados son los únicos que permiten un código completamente prediptivo. Cuando se ha obtenido un código prediptivo, se ha conseguido el cierre categorial del sistema de análisis.

Cuando se dispone solamente de un código estadístico, cabe la esperanza de llegar a elaborar alguna vez un código prediptivo, si el sistema que se está analizando es cerrado. Bastará esperar a que se logren identificar los componentes y las pertinencias todavía desconocidas. En cambio, si el sistema que se analiza es abierto, hay que renunciar a esa expectativa, a menos que se consiga transformar el sistema abierto en un sistema cerrado. Se comprende que tiene importancia fijar las reglas que permiten distinguir a unos de otros sistemas.

La diferencia fundamental que existe entre un sistema abierto y otro cerrado es la siguiente:

20. Los componentes del sistema cerrado tienen un único referente. Los componentes de un sistema abierto tienen más de un referente.

Por ejemplo, una estadística de paro ( $\underline{P S})$, presentada en cifras, sin otro comentario, remite a la situación del mercado de trabajo ( $\left.P R_{1}\right)$. Cuando el comentario acompaña a las cifras y señala, por ejemplo, los fallos estructurales que mantienen el desempleo, o las medidas políticas que es necesario llevar a cabo, los datos también remiten, para justifcarlos o rechazarlos, a un sistema de valores de referencias $\left(\underline{P R_{2}}\right)$ :

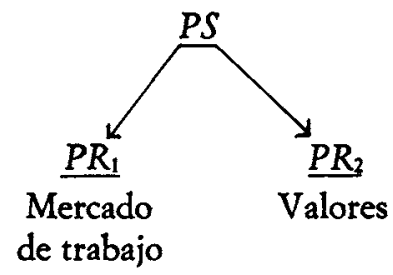


21. La condición necesaria para que un sistema de análisis posea un código prediptivo es que todos los componentes del sistema sean pertinentes respecto a un único referente. En consecuencia, la condición previa para establecer el código prediptivo de un sistema abierto consiste en averiguar si puede ser transformado en un sistema cerrado.

6) Todos los métodos que estamos describiendo tratan de transformar los sistemas de análisis abiertos que estudian en sistemas cerrados

El intento de transformar un sistema abierto en otro cerrado está muy justificado:

22. Los sistemas cerrados a otros sistemas pueden ser analizados con independencia del análisis de cualquier otro sistema como consecuencia de su cierre categorial. La pertinencia que se asigna a sus componentes puede ser validada por el recurso al análisis intrasistema.

23. Los sistemas abiertos a otros sistemas tienen que ser analizados solidariamente con el análisis de otros sistemas. La pertinencia que se asigna a sus componentes tiene que ser válida por el recurso al análisis intersistema.

Ejemplos: es posible conocer cómo funciona el reflejo de succión identificando todas las relaciones existentes entre el estado de sus componentes (hambre // saciedad del bebé; disponibilidad // no disponibilidad del pecho materno). Los componentes del sistema económico, laboral, que comparten el bebé y la madre, no afectan al sistema de un reflejo incondicionado. En cambio, el funcionamiento de sistema de comportamientos de una familia no puede ser comprendido sin tomar en cuenta la penetración del sistema económico, laboral y vecinal (eritre otros) en las relaciones que se establecen entre sus miembros.

La mayor parte de los sistemas que se estudian en las ciencias humanas son variedades de sistemas abiertos: baste mencionar los lenguajes naturales; los sistemas demográficos y económicos; las relaciones interpersonales a todos los niveles; toda la comunicación social; las organizaciones y las instituciones. Resulta necesario establecer los criterios que legitiman la transformación de un sistema abierto en otro cerrado.

24. Un sistema $\left(-S_{1}-\right)$ abierto a otros sistemas $\left(-S_{2}-\right),\left(-S_{3}-\right)$, $\left(-S_{n}-\right)$ puede ser transformado en parte de un nuevo sistema cerrado solamente cuando la integración de los estados y las trayectorias de (- $S_{1}$-), $\left(-S_{2}\right),\left(-S_{3}-\right),\left(-S_{n}-\right)$ da como resultado un sistema cerrado $\underline{S_{\mathrm{r}}}$. 
Ejemplo de cerramiento legítimo:

Sea un sistema abierto: el sistema de la expresión corporal $\left(-S_{E}-\right)$, que contiene el repertorio de gesots, tic, síntomas, etc.

$\left(-S_{E}-\right)$ aparece abierto, entre otros, a los siguientes sistemas:

$\left(-\mathrm{S}_{\mathrm{N}}-\right)$ : sistema de las necesidades profundas del individuo;

$\left(-\mathrm{S}_{\mathrm{s}}-\right.$ ): sistema del estado orgánico del individuo (su estado de salud);

$\left(-\mathrm{S}_{\mathrm{R}}-\right)$ : sistema de las relaciones cotidianas con las personas de su entorno.

El psicoanálisis clásico pretende poner en relación $\left(-S_{E}-\right)$ con $\left(-S_{N}-\right)$, en un modelo que no se vea interferido por $\left(-S_{S}-\right),\left(-S_{R}-\right)$ o cualquier otro sistema que afecte a $\left(-\mathrm{S}_{\mathrm{E}} \longrightarrow\right)$. La relación de dependencia entre $\left(-\mathrm{S}_{\mathrm{E}}-\right) \rightarrow\left(-\mathrm{S}_{\mathrm{N}}-\right)$ se conoce como «modelo de las neurosis de conversión»; y constituye, sin duda, otro sistema $\mathrm{S}_{\mathrm{NE}}$ de orden superior respecto al cual $\left(-\mathrm{S}_{\mathrm{E}}\right)$ y $\left(-\mathrm{S}_{\mathrm{N}}-\right)$ son subsistemas.

De acuerdo con 24 , si $\mathrm{S}_{\mathrm{NE}}$ es, efectivamente, un sistema cerrado (es decir, que no se ve afectado por $\left(-\mathrm{S}_{\mathrm{S}}-\right),\left(-\mathrm{S}_{\mathrm{R}}-\right)$ o cualquier otro), será legítimo el cerramiento de $\left(-\mathrm{S}_{\mathrm{E}}-\right)$, respecto a $\left(-\mathrm{S}_{\mathrm{N}}-\right)$, en el interior de $\underline{\mathbf{S}_{\mathrm{NE}}}$.

\section{ESQUEMA 5}

$\mathcal{S}_{N E}$

\begin{tabular}{|c|c|c|c|}
\hline $\begin{array}{c}\text { Sistema } \\
\text { de orden } \\
\text { superior } \\
\text { (cerrado) }\end{array}$ & $\begin{array}{l}\text { Subsistemas } \\
\text { de orden } \\
\text { inferior } \\
\text { (abiertos) }\end{array}$ & Componentes & Pertinencias \\
\hline
\end{tabular}

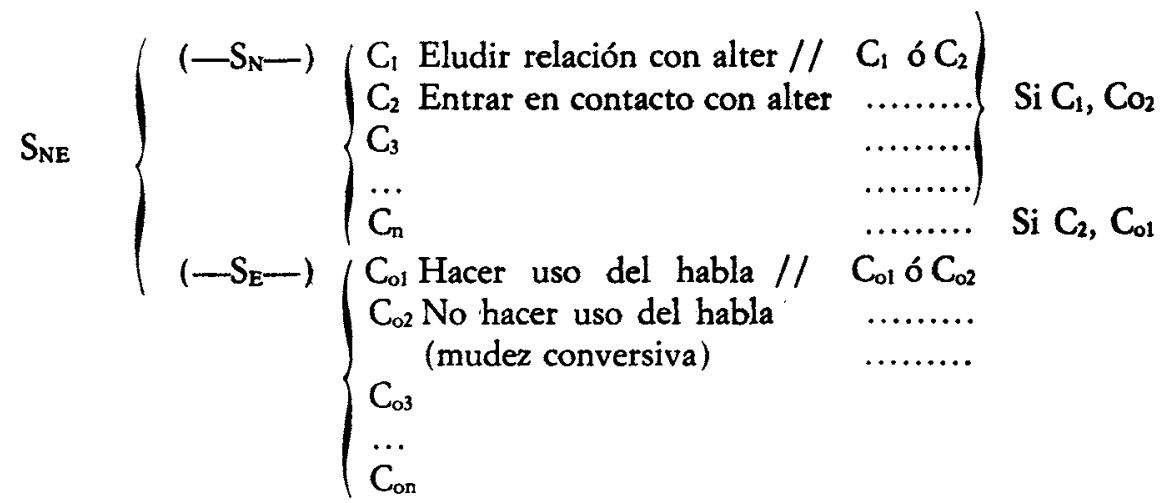

Código: $\left\{\mathrm{C}_{12} / / \mathrm{C}_{21}\right.$ 
Este ejemplo sirve para aclarar importantes cuestiones relativas al cierre categorial de los sistemas abiertos:

25. El nuevo sistema en el que se integra un sistema abierto, es de un nivel superior, y diferente, a los subsistemas de partida; es decir, está a una escala de observación distinta.

En el ejemplo que nos ocupa: $\widehat{S}_{\mathrm{NE}}$ es un sistema de análisis de la neurosis, y no un sistema de análisis de la expresión corporal (- $\mathrm{S}_{\mathrm{E}}-$ ) $n i$ un sistema de análisis de las necesidades profundas del sujeto $\left(-S_{N}-\right)$.

26. En el nuevo sistema en el que se integra un sistema abierto, no tienen por qué entrar a formar parte todos los componentes y todas las pertinencias de los subsistemas de partida.

En el ejemplo, el subsistema ( $-\mathrm{S}_{\mathrm{E}}-$ ) de expresión corporal incluye otros componentes $\left(\mathrm{C}_{03}, \ldots, \mathrm{C}_{\text {on }}\right)$, tales como «hacer uso // no hacer uso de la vista»; «moverse // no moverse», etc. Del mismo modo, el subsistema $\left(-\mathrm{S}_{\mathrm{N}}-\right)$ de las necesidades profundas incluye otros componentes $\left(C_{3}, \ldots, C_{n}\right)$ de carácter tanático o libidinal. Cada uno de los componentes introduce en su respectivo sistema, por definición, las cocorrespondientes pertinencias. Cuando el sistema de componentes y pertinencias se examinan a nivel de la neurosis a conversión, en la cura psicoanalítica, algunos componentes pierden su pertinencia, con lo que quedan excluidos por definición, y las pertinencias y componentes que se conservan en el nuevo nivel quedan articulados en relación a los criterios de discriminación que son específicos de $\mathrm{S}_{\mathrm{NE}}$ (los cuales, en este caso, quedan reflejados en el correspondiente código).

27. El nuevo sistema en el que se integra un sistema abierto tiene un código diferente de los sistemas de partida.

28. El nuevo sistema en el que se integra un sistema abierto tiene un referente distinto a los referentes de los sistemas de partida ${ }^{22}$.

El conocimiento y el respeto a estas leyes formales de los sistemas de análisis praxeológicos permite consolidar la consistencia del método. La transgresión invalida el método, como quedará de manifiesto en la tercera parte de este trabajo.

22 Fl desarrollo de los puntos 27 y 28 en forma más detallada puede encontrarse en M. Martf́ Serrano, La mediación social, Akal Edit., Madrid, 1977, págs. 73 y sigs, 
B. ANálisis de la obJETIVIDAd del SISTEMA

7) Todos los métodos praxeológicos comparten un mismo criterio de validez

La objetividad del método praxeológico se prueba, como cualquier otro, por el recurso a la referencia:

29. Un referente $R$ tiene un sistema de análisis objetivo $S$, cuando las operaciones que permite la estructura y las cualidades del sistema $S$ sirven para mostrar a $R$, o apropiarse de $R$.

30. Un sistema de análisis $S$, muestra a $R$, cuando permite reconocerle en el universo de objetos.

Decimos que un referente $R$ queda reconocido por medio de un sistema de análisis $S$ cuando las operaciones con el sistema sirven para:

advertir de su presencia;

advertir de su ausencia.

31. Un sistema de análisis $S$, sirve para apropiarse de $R$, cuando permite delimitarle en el universo de objetos.

Decimos que un referente $R$, queda delimitado por medio de un sistema de análisis $S$, cuando las operaciones con el sistema sirven para:

- la producción o aparición de $\mathrm{R}:(\overline{\mathrm{R}})$;

- la reproducción de $R:(\overline{\overline{\mathrm{R}}})$;

- la transformación o el cambio de $\mathrm{R}$ : $(\widehat{\mathrm{R}})$;

- la mutación de R: ( $\mathbb{R}$ );

- la desaparición de R: (伎).

\section{Ejemplos de reconocimiento de referentes:}

Las operaciones con el sistema de análisis del radar permite reconocer la clase de objeto del que se advierte la presencia en unas coordenadas de espacio y tiempo. Las operaciones con el sistema de análisis de las ciencias naturales en el Renacimiento permite reconocer al unicornio, objeto del que se advierte la presencia en unas coordenadas cognitivas. El sistema de categorías de análisis de contenido de la televisión permite reconocer la clase de referentes que están ausentes de los programas informativos.

Ejemplos de delimitación de referentes:

Las operaciones con el sistema de análisis de la circulación simple y ampliada sirven para la aparición, reproducción y transformación del 
modelo de producción capitalista; las operaciones con el sistema de análisis del código genético sirven para la mutación de algunas especies; las operaciones con el sistema de análisis constituido por vacunas y anticuerpos permite la desaparición de ciertas enfermedades.

Un sistema de análisis válido se representará como

$$
\mathrm{S} \rightarrow \mathrm{R}^{23}
$$

o lo que es lo mismo:

$$
\left[r \text { de } c_{1}, c_{2}, \ldots c_{n} \longleftrightarrow f \text { de }\left(c_{1}, c_{2}, \ldots, c_{n}\right)\right] \rightarrow R^{23}
$$

La elección del referente es una decisión del sujeto, en función de los objetos en los que esté interesado o a los que preste atención: por ejemplo, en este trabajo me refiero a los métodos semántico, el análisis de sistemas, la teoría de la información y sus variantes, elaborando un sistema de análisis cuya validez debe quedar justificada por referencia a $(\overline{\bar{R}})$.

\section{Análisis de la conveniencia de un sistema}

\section{8) Relaciones entre validez, objetividad y conveniencia}

El desarrollo del análisis de conveniencia plantea todo género de cuestiones metafísicas, éticas y sociológicas. Esas cuestiones forman parte, por derecho propio, de los supuestos que debe examinar una epistemología. Sin embargo, esa tarea requiere un esfuerzo que todavia no se ha hecho. En el estado actual de la praxeología cabe expresar algunas reglas canónicas que toman en cuenta la relación existente entre sistema de análisis y sistema axiológico ${ }^{24}$, supuesta la condición de validez del sistema:

32. Un sistema de análisis válido y objetivo es siempre conveniente cuando se usa con fines mostrativos. Esta regla es el reconocimiento del carácter no voluntarista de la observación objetiva.

33. Un sistema de análisis válido y objetivo, cuando delimita a un referente, tendrá necesariamente transformadas convenientes (en uno u otro mo-

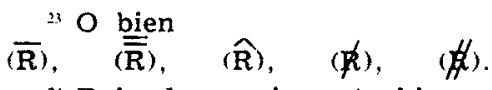

24 Dejando previamente bien sentado el carácter histórico de los valores que determinan la conveniencia del sistema -historicidad sobre la que he insistido en cada ocasión que se ha presentado. 
mento de la historia del referente) y una o varias transformadas no convenientes (en uno u otro momento de la historia del referente). De acuerdo con el concepto de sistema de análisis, se comprende que la representación canónica incluye todas las alternativas del sistema.

\section{ESTADO ACTUAL DE LA CUESTION: EN BUSCA DEL PARA. DIGMA DE LAS CIENCIAS HUMANAS}

El primer intento de elaboración de un método que sirviese de paradigma para todas las ciencias humanas se realizó por los especialistas en teoría de la información. Aquel proyecto parece ya definitivamente abandonado. En este momento existen otras nuevas tentativas de ofrecer un modelo epistemológico general para las ciencias humanas. A mi juicio, algunos de los caminos que se están ensayando no tienen salida, en tanto que hay más esperanzas en otro. En cualquier caso es posible aprender tanto de los errores como de los aciertos. Por esta razón, dedico la primera parte de este capítulo a las vías que me parecen confundidas y la segunda a aquellas que creo mejor orientadas.

III-1. Intentos QUe postulan al cierre CATEgorial COMO PROCEDiMIENTO PARA DESARROLLAR UNA EPISTEMOLOGía GENERAL

\section{a) Modalidades generales de transgresión epistemológica}

He señalado que cada uno de los métodos praxeológicos de referencia, considerado individualmente, es un método particular. Coincido con sus especialistas en que son muy útiles para hacer avanzar la epistemología de las ciencias humanas, razón por la que he entretenido la atención del lector con un análisis tan largo. Sin embargo, discrepo de aquellos que creen posible fundar una epistemología general a partir de los componentes, las pertinencias, los códigos y las referencias de una semiología, un análisis de sistemas o una teoría de la información. Mi opinión contraria se apoya en este hecho:

Sólo existe para estas metodologías un procedimiento válido de cerrar los sistemas abiertos con los que trabajan: en el marco de otro sistema más general que las incluye ${ }^{25}$.

2. La constatación de que los tres métodos praxeológicos que hemos examinado son métodos particulares, entiendo que no tiene por qué crear al cientifico que se ocupa de ellos otros problemas que los de asumir el ámbito de validez de sus trabajos. Las dificultades insolubles surgen del empeño, condenado al fracaso, de alcanzar el cierre categorial en unas metodologias que operan con sistemas abiertos. 
A mi juicio, los metodólogos que están operando con esas metodologías como si fuesen paradigmas generales de las ciencias humanas, están cometiendo algunas de estas transgresiones epistemológicas:

1. El reducionismo.

2. La generalización abusiva.

1. El reducionismo: Es la transgresión que trata de conseguir un único referente para el sistema de análisis eliminando del sistema aquellos componentes, o aquellas pertinencias que se ven afectadas por otros sistemas y, sin embargo, son necesarias para explicar sus estados y sus trayectorias; o que, conservando todos los componentes, hacen abstracción de la determinación que sobre ellos ejercen otros sistemas.

2. La generalización abusiva: Es la transgresión que transfiere a los otros sistemas, los componentes, las pertinencias o los códigos que son conocidos en el sistema abierto que se estudia, postulando a priori la identidad existente entre los modos de ser de los distintos referentes.

Ejemplo de reducionismo (véase el esquema 4 )

Sea nuevamente el sistema abierto $\left(-\mathrm{S}_{\mathrm{f}}-\right.$ ) y aquellos con los que mantiene intercambios:

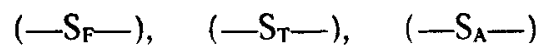

si se eliminasen los componentes y o las pertinencias de $\left(-S_{F}-\right)$, y tales pertinencias y componentes determinan el estado y la trayectoria de $\left(-\mathrm{S}_{\mathfrak{f}}-\right)$, se ha procedido a un reducionismo; es decir, la representación canónica resultante no contendría todas las transformaciones posibles de $\left(-\mathrm{S}_{\mathrm{f}}\right.$ ); el código correspondiente dejaría de generar ciertas transformaciones y generaría otras imposibles. Así ocurre, por ejemplo, en las novelas rosas cuando ignoran los condicionamientos sociales de las relaciones amorosas.

Ejemplo de generalización abusiva:

Si se transfieren los componentes y/o las pertinencias de un sistema conocido -en el ejemplo que hemos elegido (- $S_{-}-$- a otro menos conocido, por ejemplo ( $-\mathrm{S}_{\mathrm{A}}-$ ), se ha procedido a una generalización abusiva. Así, podría suponerse sin fundamento que los componentes «amor», «odio», «indiferencia» remiten a los mismos afectos que corresponden a las relaciones sociales. El código resultante adolecería de los mismos defectos que se indicaron en el caso del reducionismo. 


\section{b) Transgresiones producidas entre los semiólogos}

Estas transgresiones resultan patentes en el caso de algunos semiólogos y analistas de sistemas. Como mostraré en las próximas líneas, la semiología estudia los signos, componentes que, a nivel de contenido, están abiertos a otros sistemas no semánticos; entre otros, las motivaciones, intereses, aspiraciones de los usuarios de los signos. A su vez, los signos, a nivel de la expresión, están abiertos a otros sistemas no sintácticos, como, por ejemplo, los referentes a propósito de los cuales se usa el signo ${ }^{26}$. Un sistema semiológico es un sistema abierto, que está afectado en sus pertinencias $y$, por tanto, en sus componentes por sistemas sociales, psicológicos, axiológicos y referenciales, siendo cada uno de ellos, a su vez, otro sistema abierto.

El problema no radica en que en el interior de un sistema semiológico existan muchas pertinencias alternativas. Así ocurre, por ejemplo, con la cuestión referida a la connotación y la denotación de los signos. Que un mismo significante tenga un número muy grande de significados, no impide que sea posible encontrar un código, siempre que las pertinencias que relacionen los componentes del plano de la expresión, con los componentes del plano del contenido, se generen todas en el interior del mismo sistema. La razón por la que la semiología no logra codificar las relaciones entre expresión y contenido no derivan del enorme repertorio de pertinencias que entran en juego para establecer el campo del significado de un término, sino del hecho de que esas pertinencias también son introducidas por sistemas no semiológicos.

- Uno de los modos de transgredir las bases epistemológicas de un método praxeológico consiste en la rotura de la relación de objetividad que debe existir entre el sistema de análisis y el referente.

Por ejemplo, se puede negar de una u otra manera que la objetivación del sistema de análisis, y su verificación, tenga que justificarse por el recurso al "estado de las cosas», tal como se muestran en la realidad. Este expediente transforma un método praxeológico, en el mejor de los casos, en una mera sintáctica, es decir, en un método de transformaciones lógicas entre objetos ideales. Así ocurre, por ejemplo, en la semiología, cuando algunos autores, incómodos ante el hecho de que el lenguaje es un instrumento para intervenir sobre la realidad, y la realidad se pliega muy mal a una codificación a priori, buscan la verificación de sus sistemas de análisis en otras instancias más codificadas o más fácilmente codificables; por ejemplo, sugiriendo

2. Esta determinación es general para todo sistema de signos, con la única excepción de los sistemas artificiales automáticos y de las lógicas formalizadas. $\mathrm{Ni}$ unos ni otras son "ciencias humanas", sino técnicas. 
que todo discurso remite a otro discurso, regresión infinita que lleva a la semiología hacia la esterilidad de una retórica reverdecida.

La afirmación de que el criterio de validación de un discurso es otro discurso, puede significar dos cosas:

a) Que el criterio de objetividad no está en la realidad existente, sino en el modelo de generación de discursos. Esta pretensión es un mero idealismo, y excluye automáticamente a quienes la mantienen de los investigadores orientados hacia una epistemología de la praxis.

b) Que los referentes de la realidad están codificados del mismo modo que lo están los discursos. Quienes mantienen esta idea, están haciendo un uso abusivo del principio según el cual una misma lógica puede servir para explicar la realidad y el conocimiento. La lógica que subyace en la semiología, como bien saben sus practicantes, es una lógica articular, que opera con el principio de exclusión, y que no da cuenta del principio de contradicción. No está demostrado que el cambio y la reproducción de los referentes a los que remite la semiología obedezca precisamente a un modelo de tipo articular; tal vez, con la única excepción de los mitos. En la realidad a la que remiten los lenguajes se encuentra más frecuentemente referencias que muestran un modo de ser sujeto a la contradicción ${ }^{27}$.

La pretensión de reducir el acontecer a otro discurso supone el regreso a la forma más atrasada de metafísica, propiciada por los sofistas y luego por los cínicos, frente a la cual -y con argumentos que podrían repetirse porque siguen siendo válidos- reaccionaron Aristóteles, Duns Escoto o Suá rez ${ }^{28}$, entre otros muchos filósofos. Desde la Escuela de Atenas se ha venido señalando la distinción entre un método que se orienta a conseguir la persuasión tomando como prueba del discurso otro discurso, método llamado rerórica, practicado por los sofistas; y otro método que se orienta a conseguir la verificación, tomando como prueba del discurso el modo en el que los discursos convienen a las cosas tal como existen en cada momento histórico, método llamado dialéctica y practicado por los filósofos.

- Por otra parte, subsiste la cuestión epistemológica de la conveniencia del sistema para operar con la realidad. Los semiólogos están justamente interesados por la pragmática; y aunque no todos quieren circunscribir la práctica a las variantes que permiten sus códigos, de hecho algunos semió-

Un análisis detallado de este tema y algún ejemplo concreto, en La mediación social, $\mathrm{O}$. C., págs. $155 \mathrm{y}$ sigs.

28 De Aristóteles, Categorías, Aguilar, Buenos Aires, 1962, págs. 28 y sigs.; de DUNs Escoto, "Trabajo acerca del primer principio", en Obras del doctor Sutil, BAC, Madrid, 1960, págs. 595 y sigs; de SuÁrez, "La verdad atributo del ser", en Investigaciones metafísicas, Espasa, Buenos Aires, 1954, págs. 93 y sigs. 
logos están tratando de reducir la praxis a una semántica, empeño que, a mi juicio, es imposible ${ }^{29}$.

Evidentemente, cuando se afirma por parte de los semiólogos que las motivaciones, intereses, etc., que determinan los componentes y pertinencias de los contenidos de los signos son «semánticos» se está llevando a cabo una generalización abusiva: queda por demostrar que el campo de las aspiraciones, necesidades y valores humanos, tienen los componentes y las articulaciones de una semántica; y aún quedaría por comprobar que comparten el mismo código.

La semiología analiza un sistema abierto al acontecer. Barthes dice que el sujeto que se sitúa frente al acontecer, puede muy bien utilizar un referente como designación (signo) del propio referente. Ese uso del referente es posible; lo cual no quiere decir que todas las pertinencias que de ese referente proceden afecten exclusivamente a un sistema semántico. Los referentes de la designación también son referencias legítimas para otras prácticas no semiológicas.

Por ejemplo, cuando la televisión remite al acontecimiento de la explosión de la bomba de Hirosima, por medio de la emisión de la película que se grabó en aquella circunstancia, el telespectador puede situarse frente al referente haciendo uso de algún sistema semántico más o menos codificado. Pero, además, el telespectador sabe que esa referencia afecta a otros sistemas: por ejemplo, el de su propia supervivencia; en cuyo caso tomará en cuenta otras pertinencias, las cuales traen a colación otros sistemas de análisis, tales como "activismo para lograr el desarme», «medidas de protección en caso de explosión atómica», etc. Suponer que un sistema semántico conviene para el tratamiento de esas referencias parece gratuito; si se incluye en alguno de esos sistemas de análisis «explosión de la bomba de Hirosima», va a ser la ética, la política o la sociología, por ejemplo, y no la semiología, quienes aporten el sistema discriminativo de los componentes.

El problema no se zanja sosteniendo que existe, por una parte, un sistema semiológico que tiene un referente en ese suceso, y por otra parte, otro sistema (sociológico, ético, etc.) que remite al mismo referente. Evidentemente, con la misma referencia es posible elaborar distintos sistemas de análisis; lo que resulta imposible es cerrarlos. Porque todos los valores (extrasemiológicos) que convienen al referente

${ }^{29}$ De esta crítica hay que excluir a Hjemslev, seguidor de la tradición realista suareciana; a Baudrillard, en la medida que sigue una inspiración marxista. Ambas fuentes mantienen la tesis de que toda práctica, incluida la del uso del lenguaje, produce o transforma el sentido que se asigna al mundo. En cambio, los seguidores europeos de la escuela pragmatista de Peirce, en Bolonia, y los seguidores de la escuela idealista de Saussure, en Paris, merecen estos reproches. 
«explosión de la bomba» están presentes en el modo en el que ese referente se ofrece al sistema semiológico. No hay codificación ni hipercodificación semiológica que sea capaz de conseguir preservar al referente de un signo de su carácter finalizado ni de su historicidad. Dicho en otros términos, no es posible descentrar al sujeto, que conoce y actúa, del sistema de análisis; lo cual equivale a señalar que la semiología está abocada a aceptar los criterios de objetividad de la praxis o carecerá de toda objetividad.

La integración de un sistema semiológico - sistema abierto- con los otros sistemas que le determinan es posible dentro de ciertos límites; pero, evidentemente, la semiología se transforma en un subsistema de alguna otra metodología más general, que incluye también otras expresiones del comportamiento humano.

\section{c) Transgresiones producidas entre los analistas de sistemas}

Por lo que respecta al análisis de sistemas, la vocación de constituirse en modelo general de las ciencias aparece en el propio von Berralanffy. Los «sistemas generales» serían de aplicación en el dominio de la cristalografía, la genética, la ecología, la sociología, etc. La pretensión puede parecer desmesurada, y, sin embargo, el error no está en el exceso, sino en el defecto. Cabe encontrar algún modelo, por ejemplo, el modelo de «tensión-reducción», que sea aplicable en todos esos campos; sin embargo, tales modelos operan con una única clase de componentes: los vectores. Un modelo general debe de poder operar simultáneamente con todos los objetos que forman parte del sistema, sin tener previamente que reducirlos a una única categoría abstracta.

Cuando se estudia la tensión-reducción en un sistema de Maxwell y en un conflicto de necesidades afectivas, las pertinencias son diferentes, y son distintos los componentes. Ni los polos de fuerza engendran sufrimiento psíquico, ni los afectos motivan desviaciones de potencial en el campo eléctrico. Los componentes y las pertinencias pueden ser isomorfas, pero no son sustituibles. El análisis de sistemas reduce todo sistema de análisis a un modelo abstracto de interacción en un campo de relaciones. En consecuencia, sus aplicaciones en el dominio de las ciencias humanas son analógicas; sólo puede hacerse a costa de sustituir los componentes reales por vectores. El procedimiento posee interés heurístico en muchos casos; pero una metodología analógica no puede ser, por definición, un modelo epistemológico universal. 
III-2. INTENTOS QUE NO POSTULAN EL CIERRE CATEGORIAL COMO PROCEDIMIENTO PARA DESARROLLAR UNA EPISTEMOLOGÍA GENERAL

La teoría de la comunicación ofrece ya algunas formas de operar que están en la línea correcta para desarrollar un método praxeológico, apto para fundar una epistemología de las ciencias humanas ${ }^{30}$. Esas orientaciones son las siguientes:

A) Acepta componentes heterogéneos que, en la práctica, pueden ser cualquiera de los que se ocupan las ciencias humanas.

B) Está en condiciones de construir sistemas de análisis que respondan al carácter finalizado de los componentes y de los referentes.

C) Intenta poner en relación referentes, con sistemas de análisis y con usos.

A mi juicio, estas tres condiciones son las mínimas necesarias para que una epistemología llegue a ser adecuada como paradigma válido de las ciencias humanas.

En este momento no es posible saber si la teoría de la comunicación llegará o no a explicitar estas potencialidades; es una cuestión para la que conviene tomarse todo el tiempo preciso. En cualquier caso, parece útil trabajar sobre las posibilidades que acabo de enunciar. Las próximas líneas sugieren un punto de partida.

A) Los Modelos de aNÁlisis COMUNiCACIONAL ACEPTAN todos LOS COMPONENTES DE LOS QUE SE OCUPAN LAS CIENCIAS HUMANAS

Los componentes del sistema comunicacional son de naturaleza bete rogénea:

a) Existen componentes que son actores ${ }^{31} ; \mathrm{y}$ entre ellos es práctico distinguir entre:

3. Al sugerir que la teoria de la comunicación pueda tal vez en el futuro constituirse en una epistemologia general de las ciencias humanas, debo de aclarar que la asignación de tan trascendental función no viene determinada por moda u oficio, sino por las siguientes razones:

- En la teoría de la comunicación confluyen todas las metodologias que he analizado, al nivel de generalidad que he intentado esbozar.

- En estos últimos años los problemas epistemológicos de integración de las ciencias han interesado particularmente a quienes, siguiendo la tradición de Wiener y Shannon, son teóricos de la comunicación.

En homenaje a ellos, y por la razón práctica de que los problemas epistemológicos que aquí se tratan ocupan a teóricos de la comunicación, se justifica la elección de esta denominación para un posible paradigma, denominación que si apareciese otra más pertinente no veo inconveniente alguno en abandonar. En lo que a $\mathrm{mí}$ respecta, me interesa el contenido de una epistemología adecuada al estudio de las ciencias humanas, y no su nombre.

"Incluimos entre los actores tanto los sujetos individuales como a las instituciones que participan en la comunicación. 
a) Actores que se sirven de la comunicación (p. ej., emisores y receptores, entre los usuarios activos; audiencias y públicos, entre los pasivos) ${ }^{32}$.

$\mathrm{a}_{2}$ ) Actores que sirven a la comunicación (p. ej., todos los codificadores y decodificadores de signos, y todos los técnicos que manejan instrumentos necesarios para la transmisión de información: cámaras, mezcladores de imagen y sonido, montadores, etc.).

Evidentemente ambas funciones pueden coincidir en un mismo actor.

b) Existen componentes que son instrumentos tecnológicos; y entre ellos es práctico distinguir entre:

$b_{1}$ ) Instrumentos que se sirven de la comunicación: Aquellos que pueden ocupar en el proceso comunicativo el lugar del emisor o el receptor de comunicación, sustituyendo o complementando la intervención de un ac. tor (p. ej., los aparatos de entrada y salida de información de los sistemas de proceso de datos).

$\mathrm{b}_{2}$ ) Instrumentos que sirven a la comunicación: Aquellos que desempeñan en el proceso comunicativo la función de canal para la información entre emisores y receptores; a partir de ahora los denomino "media» ${ }^{33}$.

Nuevamente ambas funciones pueden coincidir en un mismo instrumento.

c) Existen componentes que son expresiones. Entre ellos es práctico distinguir:

$c_{1}$ ) Expresiones que son productos. Entendemos por «producto» toda cosa material que existe como consecuencia de la actividad de los hombres:

$c_{1,1}$ ) Productos concebidos para la comunicación.

Existen productos que han sido producidos precisamente para cumplir una función expresiva en el proceso comunicativo: por ejemplo, la palabra escrita, las señales indicadoras del tráfico.

$\mathrm{c}_{1,2}$ ) Productos de los que se sirve la comunicación.

La mayor parte de los productos que han sido producidos para cumplir otras funciones sociales; son «bienes», previamente a su función de expresiones: «bienes», tales como las herramientas, las casas, los vestidos. No

32 Son activos en el proceso comunicativo, por ejemplo, los interlocutores de una conversación telefónica; son pasivos, en su condición de meros espectadores de la actividad de emisores y/o receptores, por ejemplo, las audiencias de televisión.

${ }^{3}$ Son "media" el tronco hueco del que se obtienen señales acústicas por percusión, o el telégrafo óptico del que se tienen señales ópticas por reflexión. Estos media no modifican las señales que obtiene de ellos el emisor. En cambio, existen otros "media" que llevan a cabo la transmisión modificando las señales de partida. Estos media ocupan en el proceso comunicativo el lugar del codificador o el decodificador, sustituyendo o complementando la intervención del actor (por ejemplo, todas las máquinas traductoras que transforman señales luminosas, acústicas, electromagnéticas, en otra materia comunicativa: tales como la radio, el magnetoscopio, etc.). 
obstante, cualquier producto que tenga asignada primariamente una función social, por el mismo hecho termina sirviendo secundariamente de vehículo expresivo de la comunicación.

c2) Expresiones que son actos. Aquellas expresiones que consisten en una actividad del actor; por ejemplo, la palabra hablada, y todo el repertorio de gestos y posiciones expresivas que se sirven del propio cuerpo como instrumento comunicativo.

d) Existen componentes que son representaciones. Entre ellas es práctico distinguir:

$\left.\mathrm{d}_{1}\right)$ Representaciones que son modelos para la acción.

Por ejemplo, el conductor conoce un modelo de representación que establece determinadas respuestas, en función de determinados estímulos generados en la ruta y en el tablero del automóvil.

$\left.\mathrm{d}_{2}\right)$ Representaciones que son modelos para la cognición.

Por ejemplo, los códigos que deben de aprender los usuarios de los lenguajes de la comunicación: así los códigos que permiten la comprensión de las derivaciones de la química.

$\left.\mathrm{d}_{3}\right)$ Representaciones que son modelos intencionales.

Por ejemplo, el modelo que pone en relación los usos que en la práctica se asignan al sistema comunicacional, por unos u otros emisores, con los efectos (materiales, sociales, políticos, cognitivos, estéticos, culturales) que se aspira a lograr mediante la comunicación.

e) Existen componentes que son actos. Entre ellos es práctico distinguir entre:

e) Actos que afectan a los actores de la comunicación.

Aquellas prácticas que determinan la actuación o no actuación de unos $\mathrm{u}$ otros actores de la comunicación.

$\mathrm{e}_{2}$ ) Actos que afectan a los instrumentos de la comunicación.

Aquellas prácticas que determinan el empleo o el no empleo de unos u otros instrumentos de la comunicación.

e.) Actos que afectan a las expresiones de la comunicación.

Aquellas prácticas que determinan el empleo o el no empleo de unas $u$ otras expresiones comunicativas.

$\left.\mathrm{e}_{4}\right)$ Actos que afectan a las representaciones.

Aquellas prácticas que determinan el empleo o no empleo de unos u otros modelos.

B) Los MOdelos de anÁlisis COMUNICACIONAL PUEDEN DAR CUENTA DEL CARÁCTER FINALIZADO DE LOS COMPONENTES Y DE LOS REFERENTES

Los objetos finalizados se caracterizan por depender de la actividad del 
hombre; es decir, son objetos mediados. He desarrollado este tema y propuesto los correspondientes criterios de análisis, bajo la rúbrica de una teoría de la mediación en otra ocasión ${ }^{34}$, por lo que no me repetiré ahora. Solamente resulta necesario señalar que el análisis de la mediación resuelve, según creo, los siguientes problemas:

- El tratamiento de la doble referencia.

- El manejo del cambio y la reproducción de los referentes a lo largo de su existencia histórica.

- El problema de la consistencia de los códigos del sistema de análisis.

C) LOS MODELOS DE ANÁLISIS DE LA COMUNICACIÓN PUEDEN PONER EN RELACIÓN LOS REFERENTES CON LOS SISTEMAS DE ANÁLISIS Y CON LOS USOS

En la obra citada de La mediación social (pp. 107 y sigs.) he tratado el tema de los usos de la comunicación, desde el punto de vista de su objetividad respecto a los referentes. Queda otro aspecto de la objetividad muy importante por desarrollar: los usos posibles del propio sistema de análisis comunicacional desde el punto de vista de los fines que guían a los actores. Este análisis es posible, partiendo de un estudio de la centración-descentración de los componentes de la comunicación, respecto a la organización del sistema comunicacional.

A los componentes del sistema comunicacional les pueden ser asignadas (o denegadas) funciones que les son propias y funciones que corresponden, antes de la intervención humana, a otros componentes. Denomino desplazamiento de función a la práctica comunicacional que asigna una función finalizada a un componente del sistema comunicativo.

Como punto de partida, puede servir el siguiente modelo de un sistema comunicacional, que incluye todos los componentes que anteriormente he descrito ${ }^{35}$.

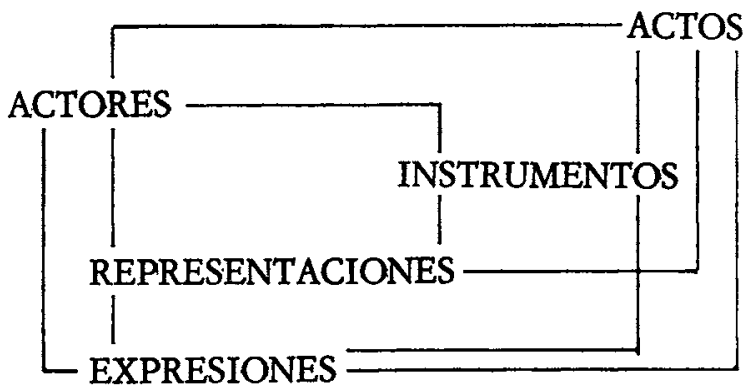

Los posibles desplazamientos funcionales quedan recogidos en los esquemas número 6 :

${ }^{34} \mathrm{Cfr}$. La mediación social, O. C., págs. 73 y sigs.

${ }^{35}$ Obviamente, este modelo excluye los referentes. 
ESQUEMAS 6

I. Desplazamientos que llevan a cabo los actores

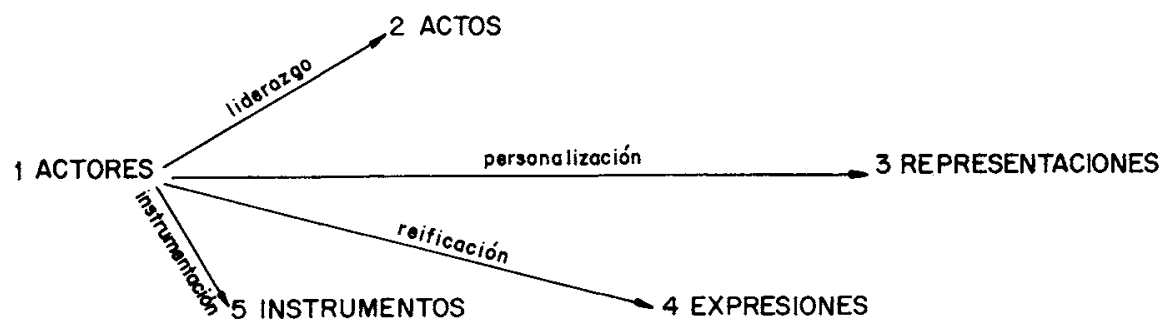

II. Desplazamientos que llevan a cabo los actos

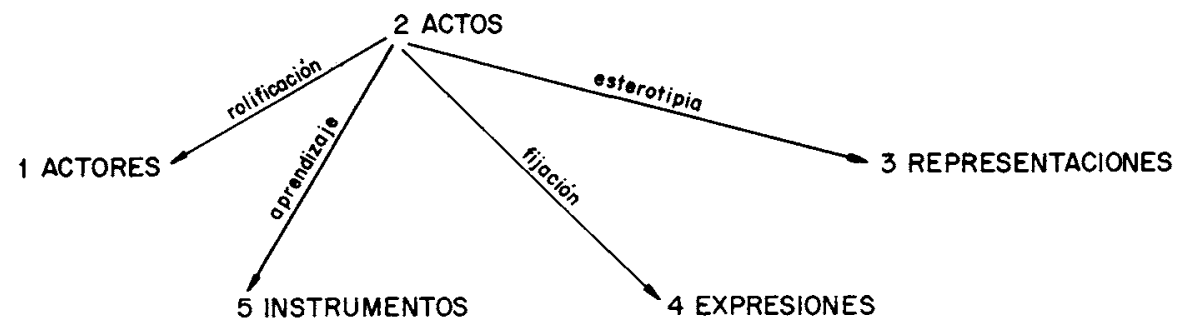

III. Desplazamientos que llevan a cabo las representaciones

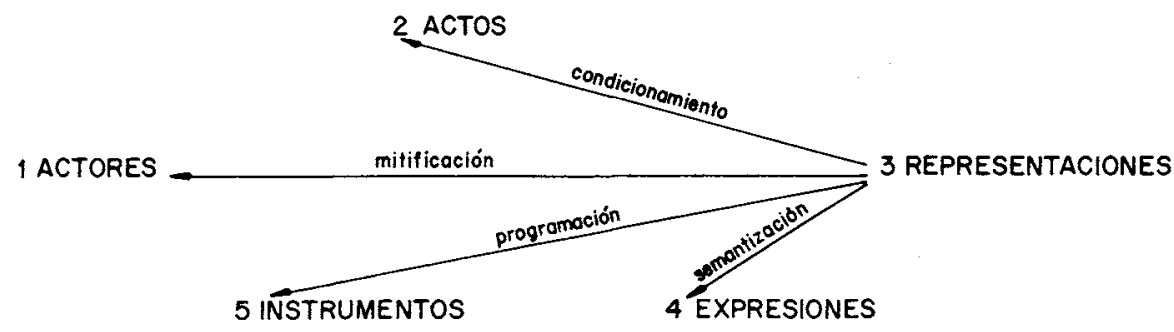


IV. Desplazamientos que llevan a cabo las expresiones

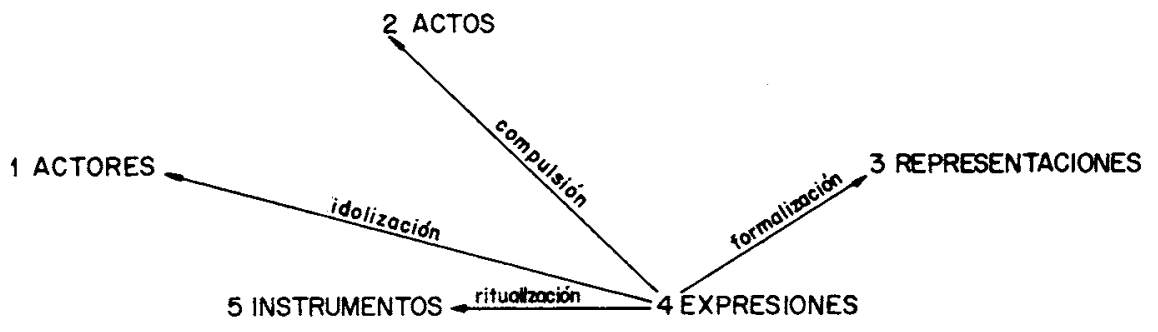

V. Desplazamientos que llevan a cabo los instrumentos

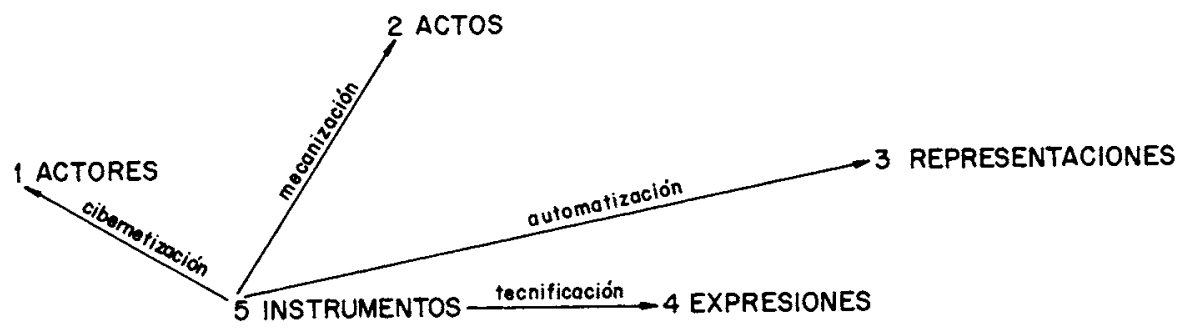


I. Desplazamientos que llevan a cabo los actores

Liderazgo.-Cuando la comunicación asigna a un actor la función de un acto; así, si se trata de alguna acción concreta que es preciso llevar a cabo encaminada a cambiar la realidad, y la comunicación ofrece como alternativa a la acción la intervención carismática de un líder; en los procesos de imprinting. El desplazamiento opuesto es la rolificación.

Personalización.-Cuando la comunicación asigna a un actor la función de una representación. Por ejemplo, cuando el modelo de «la» mujer atractiva queda asignado a una "estrella» de moda. El desplazamiento opuesto es la mitificación.

Reificación.-Cuando la comunicación asigna a un actor la función de una expresión. Por ejemplo, cuando la imagen del niño biafreño realmente hambriento sirve como expresión del signo «UNICEF». El desplazamiento opuesto es la idolización.

Instrumentación.-Cuando la comunicación asigna a un actor la función de un instrumento. Por ejemplo, cuando se usa a otro como intermediario material de unos mensajes, sea en la comunicación personal («el corre, ve y dile») o en la comunicación social (las audiencias elegidas como transmisoras y amplificadoras de opinión: amas de casa, geip-kipers, etc.). El desplazamiento opuesto es la cibernetización.

\section{Desplazamientos que llevan a cabo los actos}

Rolificación.-Cuando la comunicación asigna a un acto la función de un actor; así, cuando la intervención directa de una persona para obtener algo por sí mismo se sustituye por la cumplimentación de un formulario; cuando la evaluación de las tareas en la escuela depende de cómo se ejecuten determinadas operaciones en las máquinas de enseñanza.

Esterotipia.-Cuando la comunicación asigna a un acto la función de una representación. Por ejemplo, en los gestos que adquieren el valor de una ofensa; en la terapia laboral; en los comportamientos que fija la etiqueta en la mesa, las reuniones, etc. La función opuesta es el condicionamiento.

Fijación.-Cuando la comunicación asigna a un acto la función de una expresión. Por ejemplo, en los lenguajes artificiales basados en la dinámica del cuerpo, como las señales de banderas de los barcos, en los «tic». La función opuesta es la compulsión.

Aprendizaje.-Cuando la comunicación asigna a un acto la función de un instrumento. Así, en cualquier adquisición de un «saber hacer» práctico, que permita al individuo producir o fabricar objetos, servirse de instrumentos o comunicarse, usando solamente de sus propias habilidades manuales. La función opuesta es la mecanización. 


\section{Desplazamientos que llevan a cabo las representaciones}

Mitificación.-Cuando la comunicación asigna a una representación la función de un actor: así, en todas las formas de substantivización de los valores y las normas («el Derecho», «la Justicia» reclama); en las fuerzas de la Naturaleza o de la Sociedad que están representadas en los mitos.

Condicionamiento.-Cuando la comunicación asigna a una representación la función de un acto. Así, en todas las ocasiones en las que se invoca una norma, un modelo para eludir una intervención; como en Religión, cuando se recomienda la Fe para obtener la Justicia o la Felicidad en este mundo o el otro; o cuando el programa político se ofrece como si fuese equivalente de la acción política.

Semantización.-Cuando la comunicación asigna a una representación la función de una expresión. Ocurre en todos los discursos abstractos o icónicos cargados de ideología o presuposiciones; en ellos, los significantes son asumidos por significados; cuando la imagen de los productos o marcas sustituye en la designación al propio objeto de consumo, etc. El desplazamiento inverso es la formalización.

Programación.-Cuando la comunicación asigna a una representación la función de un instrumento. Así, cuando en los estudios de medios el modelo de los medios de comunicación de masas desplaza al examen del propio medio de comunicación, en su infraestructura y su organización concretas; cuando el modelo de una secuencia de movimientos se usa para programar máquinas, herramientas. En general, todo proceso que antes estuviese encomendado a una máquina y que luego pueda ser asumido por un modelo. El desplazamiento inverso es la automatización.

\section{Desplazamientos que llevan a cabo las expresiones}

Idolización.-Cuando la comunicación asigna a una expresión la función de un actor; por ejemplo, en el uso animista de palabras e iconos.

Compulsión.-Cuando la comunicación asigna a una expresión la función de un acto; por ejemplo: el automóvil, que es la «evasión»; la droga, que es «la elevación»; el cigarro, que es «la comunicación», etc.

Formalización.-Cuando la comunicación asigna a una expresión la función de una representación. En todos los lenguajes; por ejemplo, cuando en los discursos retóricos todos los significantes grandilocuentes que han perdido su contenido sustituyen a las ideas o los valores; cuando «el bueno" o «el malo» sustituyen en una combinatoria formalizada y siempre repetida a los contenidos de la maldad o la bondad, en los programas del cine o la televisión; cuando el paraguas real se emplea como representación de la lluvia; en las neurosis de conversión. 
Ritualización.-Cuando la comunicación asigna a una expresión la función de un instrumento. De acuerdo con Levi-Strauss, ésta es la función de toda ceremonia ritual; por ejemplo, los novenarios (véase el trabajo de J. L. Piñuel en este mismo número). El desplazamiento inverso es la tecnificación.

\section{Desplazamientos que llevan a cabo los instrumentos}

Cibernetización.-Cuando la comunicación asigna a un instrumento la función de un actor. Así ocurre en las máquinas cibernéticas; pero también sucede cuando el medio de comunicación asume el papel de dirigente del proceso comunicativo.

Mecanización.-Cuando la comunicación asigna a un instrumento la función de un acto. Así en los procesos de fabricación ligados a la segunda revolución industrial.

Automación.-Cuando la comunicación asigna a un instrumento la función de una representación; por ejemplo, la máquina de calcular que sustituye el conocimiento de las operaciones de cálculo.

Tecnificación.-Cuando la comunicación asigna a un instrumento la función de una expresión. Por ejemplo, el aparato de televisión o la antena, que asume el valor de expresar la comunicación.

El lector que me haya seguido amablemente hasta esta conclusión puede comprobar que concibo la teoría de la comunicación como un análisis solidario de los referentes, los modelos y las prácticas. Esta clase de análisis debe caracterizar precisamente a una epistemología general que se proponga dar cuenta de la validez, la objetividad y la conveniencia del saber sobre el hombre y sus obras. Proyecto de ciencia social que fue históricamente el primero que se intentó por parte de los Padres Fundadores y que en nuestros días vale la pena renovar. Hoy se parte con las ventajas que proporcionan una lógica dialéctica bien desarrollada, una teoría del conocimiento mejor fundada y un control mucho más avanzado sobre los procesos de cambio en los sistemas. 